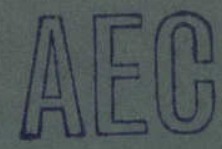

\title{
DIBUTYL CARBITOL SOLVENT EXTRACTION OF POLONIUM-210 FROM NITRIC ACID SOLUTIONS OF IRRADIATED BISMUTH
}

BY

W. W. SCHULZ AND G. L. RICHARDSON

FEBRUARY 1968

AEC RESEARCH \& DEVELOPMENT REPORT 


\section{LEGAL NOTICE}

This report was prepared as an account of Government sponsored work. Neither the United States, nor the Commission, nor any person acting on behalf of the Commission:

A. Makes any warranty or representation, expressed or implied, with respect to the accuracy, completeness, or usefulness of the information contained in this report, or that the use of any information, apparatus, method, or process disclosed in this report may not infringe privately ownéd rights; or

B. Assumes any liabilities with respect to the use of, or for damages resulting from the use of any information, apparatus, method, or process disclosed in this report.

As used in the above, "person acting on behalf of the Commission" includes any employee or contractor of the Commission, or employee of such contractor, to the extent that such employee or contractor of the Commission, or employee of such contractor prepares, disseminates, or provides access to, any information pursuant to his employment or contract with the Commission, or his employment with such contractor.

\section{PACIFIC NORTHWEST LABORATORY}

RICHLAND, WASHINGTON

operated by

BATTELLE MEMORIAL INSTITUTE

for the

UNITED STATES ATOMIC ENERGY COMMISSION UNDER CONTRACT AT(45-1)-1830 
BNWL -584

UC-4, Chemistry

\section{DIBUTYL CARBITOL SOLVENT EXTRACTION OF POLONIUM-210}

FROM NITRIC ACID SOLUTIONS OF IRRADIATED BISMUTH

\section{By}

W. W. Schulz and G. L. Richardson

Chemical Development Section

Chemistry Department

February, 1968

$\cdots$

PACIFIC NORTHWEST LABORATORY

RICHLAND, WASHINGTON 
Printed in the United States of America Available from

Clearinghouse for Federal Scientific and Technical Information National Bureau of Standards, U.S. Department of Commerce Springfield, Vírginia 22151

Price: Printed Copy $\$ 3.00 ;$ Microfiche $\$ 0.65$ 


\section{DIBUTYL CARBITOL SOLVENT EXTRACTION OF POLONIUM- 270 FROM NITRIC ACID SOLUTIONS OF IRRADIATED BISMUTH W. W. Schulz and G. L. Richardson}

\section{ABSTRACT}

A continuous countercurrent solvent extraction process utilizing dibutyl carbitol as the extractant has been developed for separating ${ }^{210}$ Po from large amounts of associated bismuth. Both laboratory and pilot plant data demonstrate the process is a suitable headend step in recovery of kilogram quantities of 210 Po. Typically, the extraction process recovers over $98 \%$ of the ${ }^{210}$ Po, essentially free from bis muth (Bi DF>1500), in a dilute $\mathrm{HNO}_{3}$ solution suitable as a starting material for final concentration and purification steps. 

TABLE OF CONTENTS

ABSTRACT

LIST OF FIGURES

LIST OF TABLES

INTRODUCTION.

SUMMARY AND CONCLUSIONS

PROCESS DESCRIPTION .

Fuel Dissolution . . . . . . . . . . 2

Solvent Extraction. . . . . . . . . . . 2

PROCESS CHEMISTRY CONSIDERATIONS. . . . . . . . 6

EXPERIMENTAL AND RESULTS. . . . . . . . . . 7

Materials . . . . . . . . . . 7

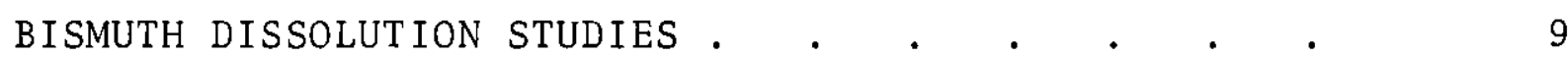

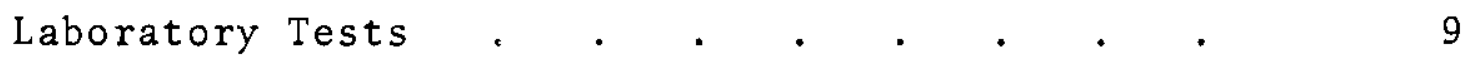

Pilot Plant Tests . . . . . . . . . . . 9

DENSITIES AND SOLUBILITIES OF Bi(NO$\left.)_{3}\right)^{-\mathrm{HNO}_{3} \cdot .} \cdot 14$ SOLUTIONS

SOLVENT EXTRACTION TESTS. . . . . . . . . . . 16

Distribution Ratio Data. . . . . . . . 16

Bismuth and $\mathrm{HNO}_{3}$ Extraction. . . . . . . 25

Mixer-Settler Runs . . . . . . . . . 29

Pilot Plant Column Runs. . . . . . . 32

Solvent Degradation Effects. . . . . . 36

Solvent Washing Techniques . . . . . . . 42

TREATMENT OF BISMUTH FRACTION $. \quad . \quad$. $\quad . \quad$. . . 44

Removal of Residual Polonium . . . . . . 44

Conceptual Scheme for Preparation . . . . 44

of Metallic Bismuth

Concentration and Acid Boiloff Studies. . . 45

Precipitation of Bismuth . . . . . . . . 46

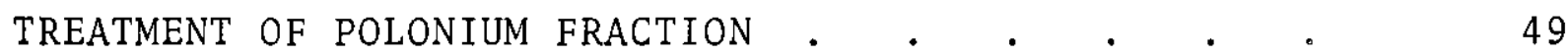

ACKNOWLEDGEMENTS . . . . . . . . . . . . . 49 


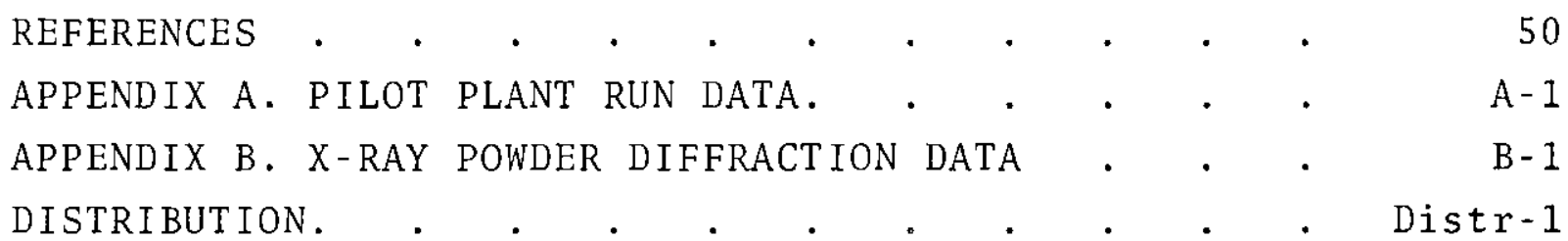




\section{LIST OF FIGURES}

1 Dissolution of Aluminum-Clad Bismuth Elements:

Process Flowsheet

2 Dibutyl Carbitol Extraction of ${ }^{210}$ Po:

Process Flowsheet

3 Instantaneous Bismuth Dissolution Rates

in Boiling $\mathrm{HNO}_{3}$

4 Effects of $\mathrm{NaNO}_{3}$ on Bismuth Dissolution

in Boiling $\mathrm{HNO}_{3}$

5 Solubility of $\mathrm{Bi}\left(\mathrm{NO}_{3}\right)_{3}$ in $\mathrm{HNO}_{3}$ at $20{ }^{\circ} \mathrm{C}$

6 Effects of Temperature and Aqueous Phase

Composition on DBC Extraction of Polonium

7 DBC Extraction of Polonium and Quadrivalent

Actinides from $\mathrm{HNO}_{3}$ Solutions

8 Comparison of Equilibrium and Nonequilibrium

Extraction of 210 Po at $25^{\circ} \mathrm{C}$

9 Effects of Contact Time on DBC Extraction

of Polonium from $\mathrm{HNO}_{3}-\mathrm{Bi}\left(\mathrm{NO}_{3}\right)_{3}$ Solutions

10 Effects of Contact Time on $\mathrm{HNO}_{3}$ Stripping

of ${ }^{210}$ Po from DBC Solutions

11 DBC Extraction of Bismuth from $\mathrm{HNO}_{3}-1 \underline{\mathrm{M}} \mathrm{Bi}\left(\mathrm{NO}_{3}\right)_{3}$

Solutions

12 DBC Extraction of $\mathrm{HNO}_{3}$ from $\mathrm{HNO}_{3}$ and $\mathrm{HNO}_{3}-\mathrm{Bi}\left(\mathrm{NO}_{3}\right)_{3}$ Solutions

$13 \mathrm{HNO}_{3}$ Concentrations Resulting from Boildown

of $\mathrm{Bi}\left(\mathrm{NO}_{3}\right)_{3}$ Solutions

14 Approximate Boiling and Freezing Points

of $\mathrm{Bi}\left(\mathrm{NO}_{3}\right)_{3}-\mathrm{HNO}_{3}$ Solutions 


\section{LIST OF TABLES}

I Radioisotopes Used in This Study 8

II Instantaneous Bismuth Dissolution Rates 12

in Boiling Solutions

II Complete Dissolution Test 13

IV Pilot Plant Dissolution Studies 13

$V \quad$ Time and Temperature Effects on Attainment 20

of Equilibrium Polonium Species

VI Mixer-Settler Runs to Demonstrate Polonium 30

Extraction Process

VII Effects on Polonium Extraction Capacity

of Heating $\mathrm{DBC}-\mathrm{HNO}_{3}$ Solutions at $50^{\circ} \mathrm{C}$

VII Effects on Polonium Extraction Capacity

of a $\mathrm{DBC}-\mathrm{HNO}_{3}$ Solution Standing at $25{ }^{\circ} \mathrm{C}$

IX Degradation of $\mathrm{DBC}$ by $\mathrm{HNO}_{3}-\mathrm{NO}_{2}^{-}$Solutions 39

$X \quad$ Effect of Organic Nitrogen Compounds on DBC 40

Extraction of Polonium

XI Alkaline Washes of Degraded DBC 42

XII Washing of Degraded $\mathrm{DBC}$ with $\mathrm{HNO}_{3}-\mathrm{KMnO}_{4}$ Solutions

XIII Precipitation of Bismuth-Decontamination Studies 48

A-1 Feed Stream Compositions for Pilot Plant Runs A-1

A-2 Pilot Plant Pulse Column Run Summaries A-2

A-3 Pilot Plant Packed Column Run Summaries A-3

B-1 X-Ray Powder Diffraction Data B-1 


\section{DIBUTYL CARBITOL SOLVENT EXTRACTION OF POLONIUM-210 FROM NITRIC ACID SOLUTIONS OF IRRADIATED BISMUTH \\ Wallace W. Schulz and Gerald L. Richardson}

\section{INTRODUCTION}

Neutron irradiation of bismuth produces 210 Po according to the reactions

$$
{ }_{83}^{209} \mathrm{Bi}+{ }_{0}^{1} \mathrm{n} \longrightarrow 83^{2} \mathrm{Bi} \underset{5 \mathrm{days}}{\longrightarrow} 210 \mathrm{Po}
$$

${ }^{210}$ po has a half 1 ife of about 138 days and decays by alpha emission to stable ${ }^{206} \mathrm{~Pb}$. Because of its short half life and high specific activity, ${ }^{210}$ Po is a valuable isotopic power source.

Separation and purification of curie amounts of ${ }^{210}$ Po have been performed for many years by the Mound Laboratory of the Monsanto Research Corporation. (1) The scheme used at the Mound Laboratory to separate ${ }^{210}$ Po from irradiated bismuth metal involves a series of deposition and redissolution steps in which the ${ }^{210}$ Po is concentrated and purified by spontaneous deposition on unirradiated bismuth powder.

This paper describes a new continuous countercurrent solvent extraction process developed as an alternative way of separating ${ }^{210}$ Po from large amounts of associated bismuth. This solvent extraction process employs dibutyl carbitol [bis(2-butoxyethy1)ether] as the extractant.

\section{SUMMARY AND CONCLUSIONS}

A dibutyl carbitol ( $D B C$ ) solvent extraction process for recovery and purification of 210 Po from $\mathrm{HNO}_{3}$ solutions of irradiated bismuth metal is described. The process is an efficient, high capacity processing technique suitable as a headend step in recovery of kilogram quantities of ${ }^{210}$ Po for subsequent uses in isotopic power sources. 
The separation scheme involves selective countercurrent extraction of polonium from an aqueous $\mathrm{HNO}_{3}-\mathrm{Bi}\left(\mathrm{NO}_{3}\right)_{3}$ feed solution containing about $4 \mathrm{Ci}$ per liter of ${ }^{210}$ Po into approximately a double volume portion of $\mathrm{DBC}$. The resulting organic extract is scrubbed with $3 \mathrm{M}_{-} \mathrm{HNO}_{3}$ to provide further decontamination from bismuth. Polonium is then stripped into a $0.2 \mathrm{MNO}_{3}$ solution. The resulting aqueous solution is considered a suitable starting material for final concentration and purification of the ${ }^{210}$ Po. Laboratory and pilot plant tests demonstrate overall bismuth decontamination factors to be typically 1500 or higher.

\section{PROCESS DESCRIPTION}

\section{FUEL DISSOLUTION}

The bismuth target elements currently irradiated in Hanford reactors are $6 \mathrm{in}$. 1ong, $1.34 \mathrm{in}$. in diameter, and weigh $3.01 \mathrm{lb}$, They are clad in an aluminum can with a 0.035 in. wall thickness. The bismuth is irradiated to yield about $6 \mathrm{Ci}$ of ${ }^{210} \mathrm{Po}$ per $1 \mathrm{~b}$ of bismuth $\left(2.5 \mathrm{~g}\right.$ of ${ }^{210}$ Po per ton of bismuth).

The aluminum cans are removed by dissolution in a $\mathrm{NaOH}-\mathrm{NaNO}_{3}$ solution in accordance with well established techniques for decladding irradiated reactor fuel elements。(2) The bismuth is then dissolved in boiling dilute $\mathrm{HNO}_{3}$ to prepare extraction column feed stock (1AF solution). A satisfactory dissolution procedure is to start the dissolution reaction in a minimum volume of 4 to $6 \mathrm{M} \mathrm{HNO}_{3}$ and then add concentrated $\mathrm{HNO}_{3}$ periodically over a 1 to 2 -hr period, A chemical flowsheet for the decladding and dissolution operations is given in Figure 1.

SOLVENT EXTRACTION

A detailed chemical flowsheet for the $D B C$ extraction separation of 210 Po from bismuth in the $1 \mathrm{AF}$ solution is shown in Figure 2. Principal features of the extraction process are: 


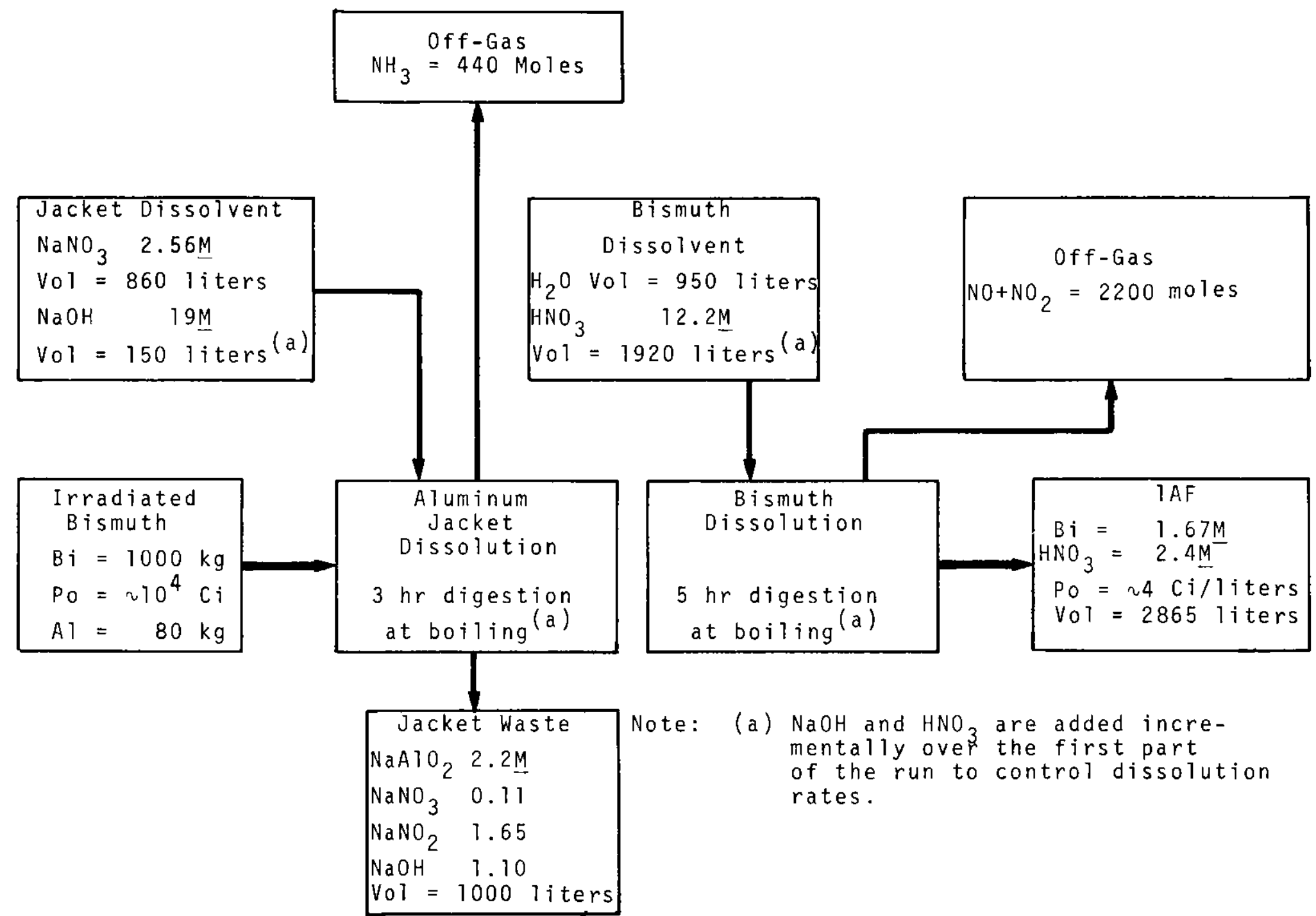

FIGURE 1. Dissolution of Aluminum-Clad Bismuth Elements: Process Flowsheet 


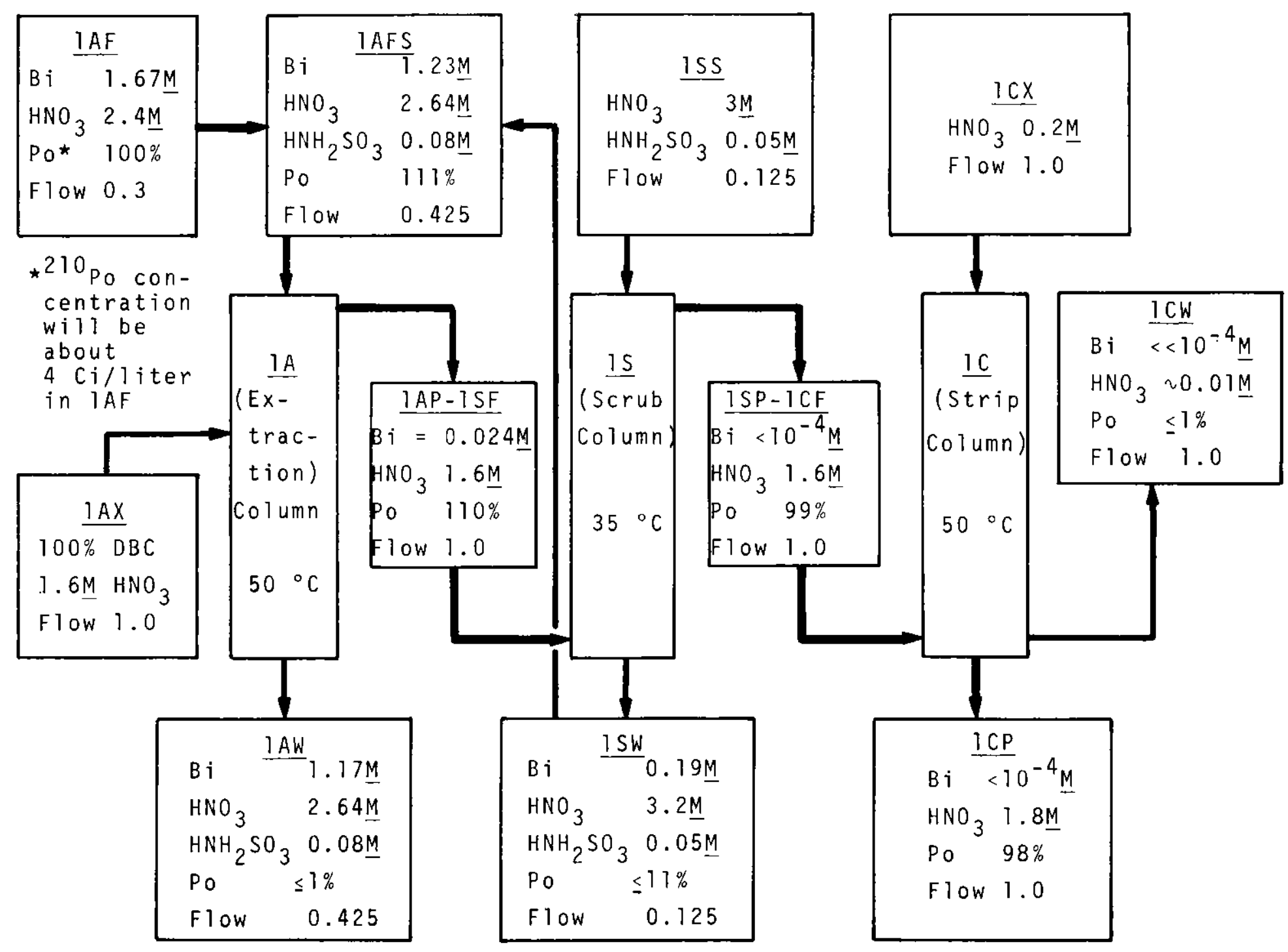

FIGURE 2. Dibutyl Carbitol Extraction of ${ }^{210}$ Po: Process Flowsheet 
- 210 Po is preferentially (>98\%) extracted by the DBC solvent in the extraction column. About 2 to $8 \%$ of the bismuth is also extracted.

- Most of the extracted bismuth is removed from the DBC phase by contacting it with a small volume of $3 \mathrm{M}^{\mathrm{HNO}} 3$ in the scrub column. The aqueous raffinate from the scrub column is routed to the extraction column to recover the small amounts of ${ }^{210}$ Po which are also scrubbed from the organic phase.

- A dilute $\mathrm{HNO}_{3}$ solution is used in the strip column to strip the purified ${ }^{210}$ po from the organic phase. The resulting aqueous solution is considered a suitable starting material for final concentration and purification of the ${ }^{210}$ Po by chemical or electrolytic deposition techniques.

- The process provides for recovery of over $98 \%$ of the ${ }^{210}$ Po with an overall bismuth decontamination factor of greater than 1500 .

Successful operation of the extraction process requires careful control of the $\mathrm{HNO}_{3}$ concentration in the various aqueous and organic streams. Of particular concern is the $\mathrm{HNO}_{3}$ concentration in the extraction column since $\mathrm{BiONO}_{3} \cdot \mathrm{H}_{2} \mathrm{O}$ will begin to precipitate if the $\mathrm{HNO}_{3}$ concentration falls below about $0.8 \mathrm{M}$. (3) The required control of $\mathrm{HNO}_{3}$ concentration in the extraction column is achieved by proper adjustment of flow ratios and also by adjusting the DBC to about $1.6 \mathrm{M} \mathrm{HNO}_{3}$ before introducing it into the process. Control of the $\mathrm{HNO}_{3}$ concentration in the scrub and strip columns is provided by selection of flow ratios and scrub and strip solution acidities.

Equilibrium $\mathrm{DBC}$ extraction of polonium from $\mathrm{HNO}_{3}-\mathrm{Bi}\left(\mathrm{NO}_{3}\right)_{3}$ solutions is established more rapidly at $50{ }^{\circ} \mathrm{C}$ than at $25{ }^{\circ} \mathrm{C}$. The extraction column is operated at $50{ }^{\circ} \mathrm{C}$, therefore, to ensure both the reproducible extraction behavior and the transfer kinetics commensurate with phase residence times encountered 
in conventional pulse or packed column equipment. Increase in temperature depresses equilibrium 210 po distribution coefficients. To overcome this effect, a large flow of solvent is required in the extraction column. Conversely, the effect of increased temperature in lowering ${ }^{210}$ Po distribution coefficients is effectively employed in the strip column to aid removal of the polonium from the organic phase,

Finally, sulfamic acid is added to the extraction column feed stock and to the scrub $\mathrm{HNO}_{3}$ solution to react with and destroy any nitrite ion or HONO which might be present. Degradation of the $\mathrm{DBC}$ by reaction with $\mathrm{HNO}_{3}$ is catalyzed by nitrite ion.

\section{PROCESS CHEMISTRY CONSIDERATIONS}

Polonium is presumed to exist in the +4 oxidation state in the dilute $\mathrm{HNO}_{3}$ solutions used in the $\mathrm{DBC}$ extraction process since this is the most stable oxidation state of polonium in aqueous solution. (4) Some evidence suggests that anionic nitrate complexes such as $\mathrm{Po}\left(\mathrm{NO}_{3}\right)_{5}^{-}$and $\mathrm{Po}\left(\mathrm{NO}_{3}\right)_{6}^{2-}$ exist in concentrated $(>\underline{6}) \mathrm{HNO}_{3}$ solutions. $(4,5)$

Extraction of polonium from $\mathrm{HNO}_{3}$ solutions by organic solvents has not been studied extensively although important contributions have been made by Matsuura and coworkers, $(6,7)$ by Cairo, (5) and by Donnan and Zamith. (8) Respectively, these workers studied extraction of polonium by methylisobutylketone, diisopropylketone, and various ethers and alcohols. The most recent studies are those of Sheppard $(9,10)$ who surveyed extraction of both polonium and bismuth from $\mathrm{HNO}_{3}$ solutions by several phosphate esters and long chain amines as well as by various oxygenated solvents. The best polonium-bismuth separations were obtained with the oxygenated solvents.

Sheppard's results were instrumental in the choice of DBC as the extractant to be used in laboratory and pilot plant 
development of a solvent extraction process for recovery and purification of kilogram amounts of ${ }^{210}$ Po. For application in such a process, $D B C$ has the desirable qualities of a high flash point, of being readily available on a commercial scale, and of acceptably separating ${ }^{210}$ po from bismuth. Previous plant scale use of DBC in solvent extraction schemes has included the British Butex process $(11,12)$ for separation of uranium and plutonium from fission products and, in the United States, for recovery of ${ }^{235} \mathrm{U}$ from various waste solutions produced in final processing of enriched uranium solutions.(13)

Many of the properties and reactions of $D B C$ are fairly well known because of the early plant applications. A particularly important and undesirable property of $D B C$ is its reaction with moderately concentrated $\mathrm{HNO}_{3}$, sometimes with explosive violence. Reaction of $\mathrm{DBC}$ with $\mathrm{HNO}_{3}$ leads ultimately to $\mathrm{CO}_{2}$ and water. Intermediate oxidation products include mono-n-butyl cellosolve, mono-n-butyl carbitol, and oxalic and butyric acids. (14) The extent of the degradation reaction depends on the $\mathrm{HNO}_{3}$ concentration and temperature. Degradation of $\mathrm{DBC}$ by $\mathrm{HNO}_{3}$ is catalyzed by HONO and nitrite ion. The importance of nitrite catalysis was first established by Susano ${ }^{(14)}$ who found that the degradation reaction is not initiated in the absence of HONO or nitrite ion. Anticipating results discussed in detail later, our work has shown that a first step in the degradation reaction appears to be formation of an organic nitrite compound which interferes strongly with extraction of polonium.

EXPERIMENTAL AND RESULTS

MATERIALS

Unirradiated and unclad bismuth fuel elements were used in metal dissolution studies and in preparing feed for cold 
pilot plant extraction tests. Extraction column feed stock for mixer-settler runs was prepared by $\mathrm{HNO}_{3}$ dissolution of mechanically declad fuel elements which had been irradiated in Hanford reactors and then stored 2 to 11 months after discharge from the reactor.

Dibutyl carbitol from the Union Carbide Chemical Co. was used as received. This material contains about 5 vol\% of an unidentified acidic impurity, but sheppard $(9)$ found earlier that polonium and bismuth distribution ratios were not influenced by the presence of this contaminant.

Organic nitrogen compounds were added deliberately to the $\mathrm{DBC}$ in some experiments to test their effect on polonium extraction. Butyl and octyl nitrites were procured from Distillation Products Industries. Octyl nitrate and nitro-octane were prepared by E. C. Martin of this laboratory from procedures described in the literature. $(15,16)$

Radioisotopes used in studies of the precipitation of $\mathrm{BiONO}_{3} \cdot \mathrm{H}_{2} \mathrm{O}$ from $\mathrm{Bi}\left(\mathrm{NO}_{3}\right)_{3}-\mathrm{HNO}_{3}$ solutions are listed in Table I. ${ }^{5} 1_{\mathrm{Cr}}$ was obtained from Oak Ridge National Laboratory ${ }^{22} \mathrm{Na}$ was procured from Abbott Laboratories and all other isotopes were obtained from New England Nuclear Corporation.

TABLE I. Radioisotopes Used in This Study

\begin{tabular}{|c|c|c|}
\hline Radioisotope & Chemical & Form \\
\hline${ }^{59} \mathrm{Fe}$ & $\mathrm{Fe}(\mathrm{III})$ & in $\mathrm{HCl}$ \\
\hline${ }^{51} \mathrm{Cr}$ & $\operatorname{Cr}(\mathrm{I} I \mathrm{I})$ & in $\mathrm{HCl}$ \\
\hline${ }^{54} \mathrm{Mn}$ & $\mathrm{Mn}(\mathrm{II})$ & in $\mathrm{HC} 1$ \\
\hline${ }^{60} \mathrm{Co}$ & $\mathrm{Co}(\mathrm{II})$ & in $\mathrm{HCl}$ \\
\hline $125 \mathrm{Sb}$ & $\mathrm{Sb}(\mathrm{I} I \mathrm{I})$ & in $\mathrm{HCl}$ \\
\hline${ }^{110} \mathrm{Ag}$ & $\mathrm{Ag}(\mathrm{I})$ & in $\mathrm{HNO}_{3}$ \\
\hline${ }^{22} \mathrm{Na}$ & $\mathrm{NaCl}$ & in $\mathrm{H}_{2} \mathrm{O}$ \\
\hline $182 \mathrm{Ta}$ & $\mathrm{Ta}$ & in $\mathrm{KOH}$ \\
\hline
\end{tabular}


BISMUTH DISSOLUTION STUDIES

Laboratory Tests

Laboratory dissolution tests were made to establish optimum dissolution conditions in an existing pilot plant dissolver. (17) The tests included both instantaneous dissolution studies with wafers cut from a fuel element, and complete dissolution of one-half of a fuel element.

The results of the instantaneous tests are presented in Table II and Figures 3 and 4 . (The data points are averages of at least 2 determinations agreeing within $\pm 10 \%$ ). The data were obtained by inserting bismuth wafers into boiling $\mathrm{HNO}_{3}$ solutions and measuring the weight loss as a function of dissolution time. Several of the acid solutions also contained either $\mathrm{NaNO}_{3}$ or $\mathrm{Al}\left(\mathrm{NO}_{3}\right)_{3}$ to serve in independently determining the effect of nitrate ion on dissolution.

In the complete dissolution test, one-half of a fuel element was suspended in a reflux dissolver initially containing $500 \mathrm{ml}$ of boiling $4 \mathrm{M} \mathrm{HNO}_{3}$. Nitric acid was added in increments every 10 to $20 \mathrm{~min}$ to maintain the acidity at about $3 \pm 1 \mathrm{M} \mathrm{HNO}_{3}$. The dimensions of the element were measured at these times and sample aliquots were withdrawn for analysis. The results of this test are shown in Table III. About $10 \%$ of the bismuth was undissolved at the end of the final dissolution period. The average $\mathrm{HNO}_{3}$ consumption was 4 moles per mole of bismuth dissolved.

Pilot Plant Tests

Dissolution runs in the pilot plant dissolver confirmed the laboratory results. A summary of the pilot plant data is presented in Table IV. 


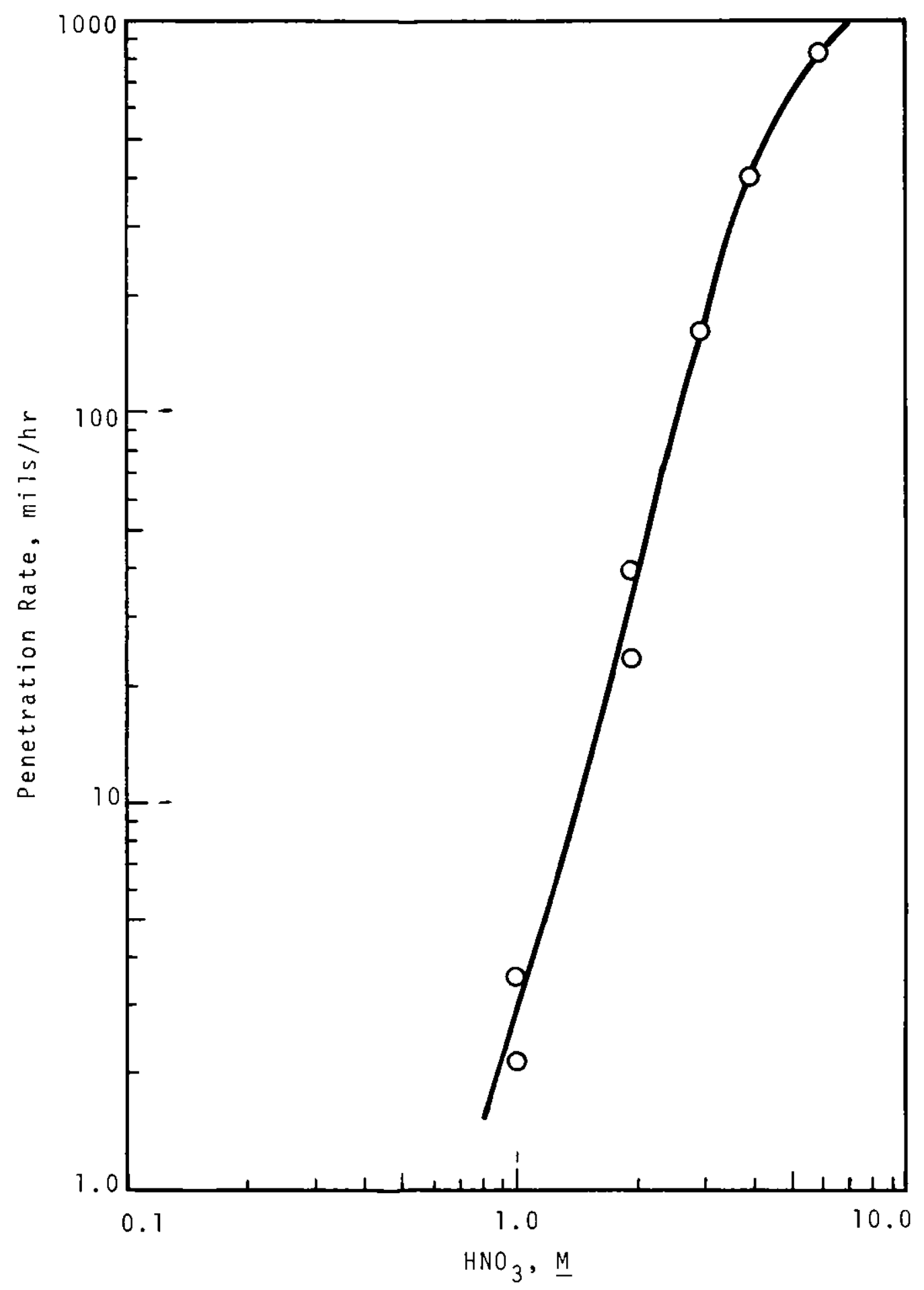

FIGURE 3. Instantaneous Bismuth Dissolution Rates in Boiling $\mathrm{HNO}_{3}$ 


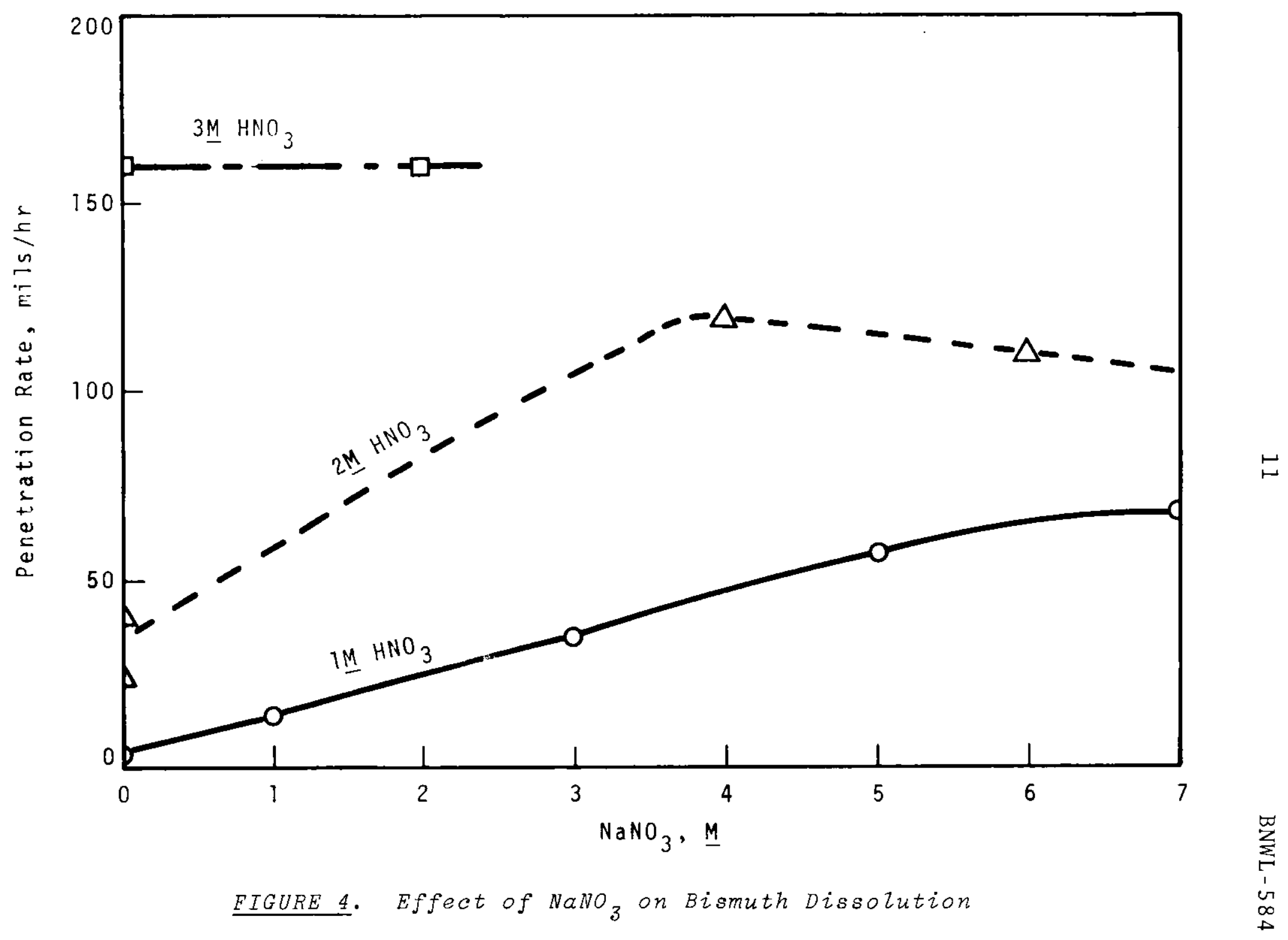


The pilot plant dissolution runs were normally started by covering the bismuth elements with water, heating to boiling, and adding $12.2 \mathrm{MNO}_{3}$ incrementally to maintain the acidity at about 3 to $4 \mathrm{M}$. The addition rate was dictated partly by the rate of gas evolution and by foaming of the dissolver solutions. (The dissolver had about 20 in. of freeboard above the liquid surface, and the foam level in Run 2 reached within 1 in. of the top).

\section{TABLE II. Instantaneous Bismuth Dissolution Rates in Boiling Solutions}

\begin{tabular}{|c|c|c|c|c|c|}
\hline $\begin{array}{l}\text { Dissolven } \\
\frac{\mathrm{HNO}_{3}}{3}\end{array}$ & $\frac{n t \text { Compc }}{\mathrm{NaNO}_{3}}$ & $\frac{\text { sition, }}{\mathrm{Al}\left(\mathrm{NO}_{3}\right)_{3}}$ & $\begin{array}{l}\text { Dissolution } \\
\text { Rate, } \\
\mathrm{mg} / \mathrm{min} \mathrm{cm}^{2}\end{array}$ & $\begin{array}{l}\text { Penetration } \\
\text { Rate } \\
\text { mil/hr }\end{array}$ & $\begin{array}{l}\text { Boiling } \\
\text { Temp., }{ }^{\circ} \mathrm{C}\end{array}$ \\
\hline 1 & 0 & 0 & 1.5 & 3.5 & 102 \\
\hline $1^{\text {(a) }}$ & 0 & 0 & 0.9 & $2.1^{\text {(a) }}$ & 102 \\
\hline 2 & 0 & 0 & 9.5 & 23 & 104 \\
\hline $2^{(a)}$ & 0 & 0 & 16 & $39^{(a)}$ & 104 \\
\hline $3^{(a)}$ & 0 & 0 & 65 & $160^{(a)}$ & 104 \\
\hline 4 & 0 & 0 & 134 & 400 & 107 \\
\hline 6 & 0 & 0 & 340 & 820 & 110 \\
\hline 1 & 1 & 0 & 5.7 & 14 & 104 \\
\hline I & 3 & 0 & 14 & 34 & 107 \\
\hline 1 & 5 & 0 & 23 & 56 & 109 \\
\hline 1 & 7 & 0 & 28 & 67 & 111 \\
\hline 2 & 4 & 0 & 50 & 120 & 107 \\
\hline 2 & 6 & 0 & 47 & 110 & 112 \\
\hline 3 & 2 & 0 & 65 & 160 & 107 \\
\hline 1 & 0 & 1 & 15 & 36 & 106 \\
\hline 2 & 0 & 2 & 69 & 170 & 113 \\
\hline
\end{tabular}

(a) Test coupon was one-half of a fuel element labout 10-fold Zarger than other coupons). 
TABLE III. Complete Dissolution Test

\begin{tabular}{|c|c|c|c|c|c|c|c|}
\hline $\begin{array}{c}\text { Sample } \\
\text { No. }\end{array}$ & $\begin{array}{l}\text { Dissolution } \\
\text { Time, min }\end{array}$ & $\frac{M}{\text { Start }}$ & $\frac{3}{\text { End }}$ & $\begin{array}{l}\text { Final } \\
\text { Bi } \underline{M}\end{array}$ & $\begin{array}{r}\text { Dissolution Rate, } \\
\mathrm{mg} / \mathrm{min} \mathrm{cm}^{2}\end{array}$ & $\begin{array}{r}\text { Penetration Rate, } \\
\mathrm{mi} 1 / \mathrm{hr}\end{array}$ & $\begin{array}{c}\text { Final Boiling } \\
\text { Temp. }{ }^{\circ} \mathrm{C} \\
\end{array}$ \\
\hline 1 & 12 & 4.0 & 1.90 & 0.62 & 55 & 130 & - \\
\hline 2 & 21 & 3.35 & 1.65 & 0.97 & 27 & 64 & 104 \\
\hline 3 & 16 & 3.77 & 1.94 & 1.30 & 43 & 103 & 105 \\
\hline 4 & 15 & 3.82 & 2.44 & 1.45 & 54 & 129 & 106 \\
\hline 5 & 14 & 3.94 & 2.78 & 1.59 & 58 & 140 & 105 \\
\hline 6 & 14 & 4.09 & 3.02 & 1.73 & 61 & 146 & 108 \\
\hline 7 & 16 & 4.21 & 3.05 & 1.81 & 66 & 158 & 107 \\
\hline 8 & 19 & 4.11 & 3.19 & 1.90 & 66 & 160 & - \\
\hline 9 & 25 & 4.17 & 2.97 & 2.02 & 64 & 153 & - \\
\hline 10 & 30 & 3.54 & 3.0 & 2.35 & 54 & 131 & - \\
\hline
\end{tabular}

TABLEIV. Pilot Plant Bismuth Dissolution Studies

\begin{tabular}{|c|c|c|c|c|}
\hline Ru & & \multicolumn{2}{|c|}{$\underline{\mathrm{M}} \mathrm{HNO}_{3}$} & \\
\hline No. & $\mathrm{Bi}$ & Start & End & $\mathrm{Avg}$ \\
\hline 1 & 150 & 4 & 3.2 & 3.2 \\
\hline 7 & 288 & 3.9 & $3.3(b)$ & 3.4 \\
\hline $\begin{array}{l}3 \\
4\end{array}$ & $\begin{array}{l}283 \\
286\end{array}$ & $\begin{array}{r}6.1 \\
12.2\end{array}$ & $\begin{array}{l}2.3 \\
1.4\end{array}$ (b) & $\begin{array}{c}3.2 \\
(3.8)\end{array}$ \\
\hline (a) & 27 & 8.1 & $(3.0)$ & $(3.9)$ \\
\hline
\end{tabular}

\begin{tabular}{ccccc}
$\begin{array}{c}\text { Acid Addition } \\
\text { Time, hrs }\end{array}$ & $\begin{array}{c}\text { Dissolution } \\
\text { Time, hrs }\end{array}$ & $\begin{array}{c}\text { \% } \\
\text { Dissolved }\end{array}$ & $\begin{array}{c}\text { Final } \\
\text { Bi, M }\end{array}$ \\
\cline { 1 - 1 } 3.3 & & 4.0 & & \\
2.6 & & 4.1 & $>99$ & 1.93 \\
1.7 & 4.9 & 99 & 1.92 \\
0.7 & 5.5 & 90 & 1.74 \\
$(0)$ & 2.5 & 100 & $(1.4)$
\end{tabular}

Moles Acid Used

per mole $B i$ Penetration Rate

Average

(a) Heel from Run 4.

(b) Partially neutralized by overflow of $\mathrm{NaOH}$ from off-gas scrubber.

(c) Low rate due to low temperature during first 2.5 hours of the run and to partial acid neutralization during the final period of the run (see note $b$ ). 
Run 4 was a departure from the standard procedure in that the total acid requirement was charged to the cold dissolver as 12. $2 \mathrm{M} \mathrm{HNO}_{3}$ and heated slowly. The reaction began at $50{ }^{\circ} \mathrm{C}$ and became vigorous enough at $65{ }^{\circ} \mathrm{C}$ for the $\mathrm{NO}_{2}$ fumes to overwhelm the off-gas scrubbing system. The reaction was slowed by diluting the acid with water to a nominal $11,1 \underline{M}$ and cooling it to $55{ }^{\circ} \mathrm{C}$. After about an hour, the temperature was slowly raised to boiling without further incident. The reaction evidently was only slightly exothermic. While the heat to the dissolver was off, the dissolver temperature leveled off at $54{ }^{\circ} \mathrm{C}$. The reaction during the other runs also was observed to subside quickly whenever the steam to the dissolver was shut off.

Excellent acid economy was achieved in these runs. An average of only 3.45 moles of $\mathrm{HNO}_{3}$ was used per mole of bismuth dissolved, compared with the theoretical minimum of three for the overall reaction

$$
\mathrm{Bi}+3 \mathrm{HNO}_{3}+0.750_{2} \rightarrow \mathrm{Bi}\left(\mathrm{NO}_{3}\right)_{3}+1.5 \mathrm{H}_{2} \mathrm{O}
$$

The economy was achieved with a downdraft reflux condenser in which the off-gases were passed down through a packed condenserabsorber.

DENSITIES - SOLUBILITIES OF Bi(

The densities of the $\mathrm{Bi}\left(\mathrm{NO}_{3}\right)_{3}$ solutions obtained in the dissolution studies just discussed were found to fit the equation

$$
\mathrm{d}_{25}{ }^{\circ} \mathrm{C}=1.0012+0.3045(\underline{\mathrm{M} \mathrm{Bi}})+0.03096\left(\underline{\mathrm{M}} \mathrm{HNO}_{3}\right)
$$

with an accuracy of $\pm 1.4 \%$ over the range studied (see Tables III and IV).

The data in Tables III and IV, together with that of Rutten and Van Bemmelen ${ }^{(3)}$ were used to calculate $\mathrm{Bi}\left(\mathrm{NO}_{3}\right)_{3}$ solubilities in $\mathrm{HNO}_{3}$ at $20{ }^{\circ} \mathrm{C}$. The results are plotted in Figure 5. Solubilities are considerably higher in heated solutions, and concentrations as high as $4 \mathrm{M}$ Bi have been obtained in boiling solutions. 


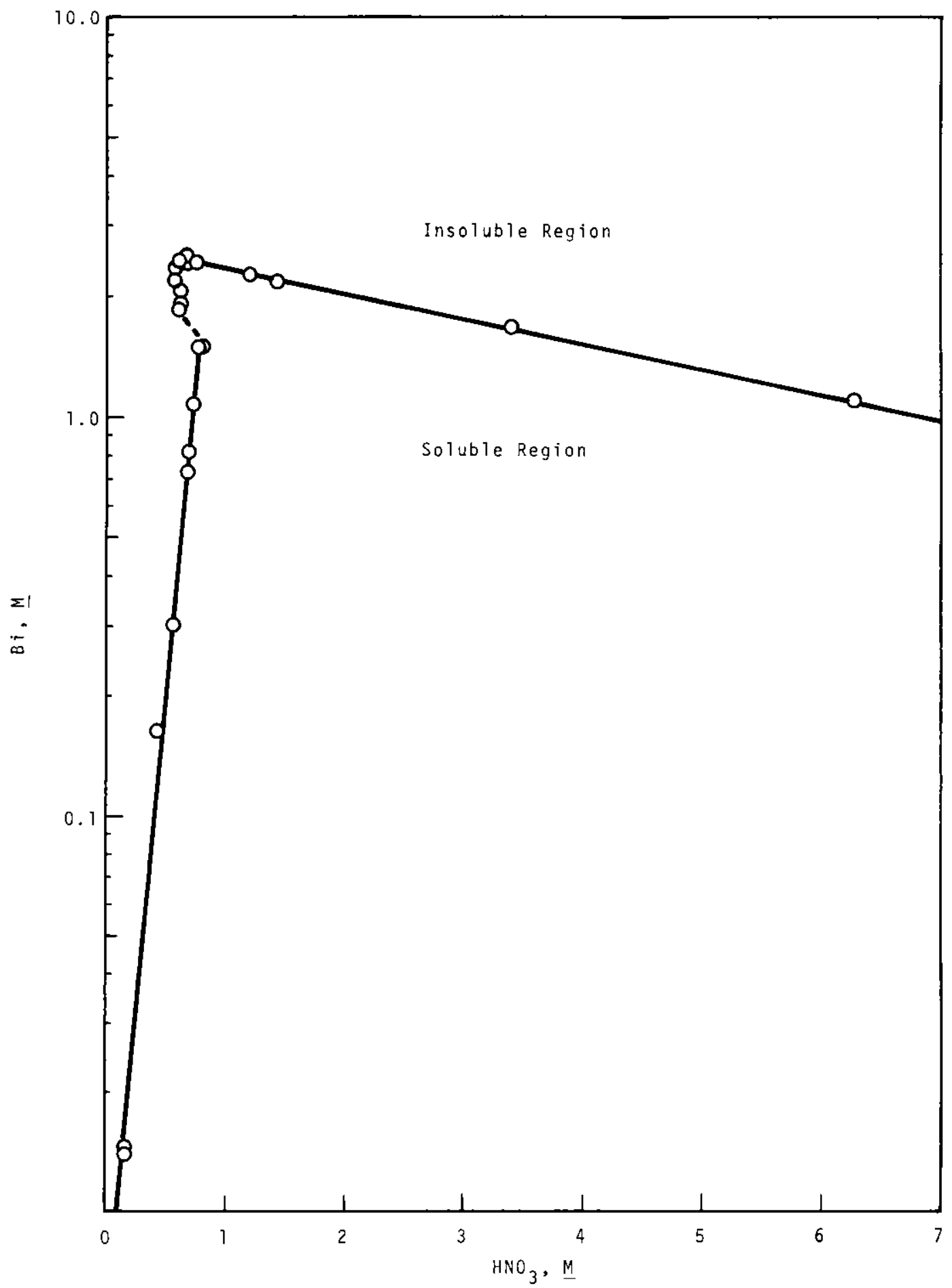

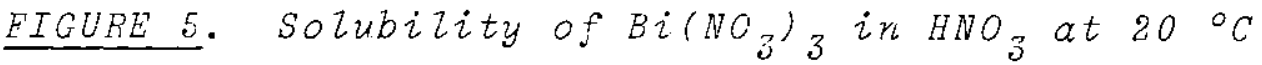


SOLVENT EXTRACTION TESTS

Distribution Ratio Data

The distribution ratio $\left(E_{a}^{0}\right)$ is defined as the ratio of the concentration of the element of interest in the less dense organic phase to the concentration of the element in the more dense aqueous phase after equilibration of the two essentially immiscible 1iquids. Phases were contacted by mechanical stirring, and separated by either centrifugation or gravity settling. Temperatures were controlled to $\pm 0.5{ }^{\circ} \mathrm{C}$ during the contact period. Except where the effect of contact time was studied, a standard 10 -min contact time was allowed for attainment of equilibrium at $50{ }^{\circ} \mathrm{C}$ while, at $25^{\circ} \mathrm{C}$ and $35{ }^{\circ} \mathrm{C}$, the standard contact time was $30 \mathrm{~min}$. Unless otherwise indicated, equal volumes of aqueous and DBC solutions were used.

\section{Polonium Extraction Studies}

Equilibrium Distribution Data. Solutions of the composition 2. to $6 \mathrm{M}^{-1 N^{-1}} \mathrm{Hi}_{3}\left(\mathrm{NO}_{3}\right)_{3}$, each containing about $3 \mathrm{Ci}$ per liter of $21 \overline{0}^{\mathrm{Po}}$, were prepared by adding water or $15.6 \mathrm{M} \mathrm{HNO}_{3}$ to a lAF solution obtained by dissolving irradiated bismuth metal in $\mathrm{HNO}_{3}$. These solutions were allowed to stand for one week at $25^{\circ} \mathrm{C}$ to ensure establishment of equilibrium polonium species. Each of the equilibrium solutions was contacted with $\mathrm{DBC}$ at both 25 and $50^{\circ} \mathrm{C}$ at an aqueous-to-organic volume ratio of 0.425 .

A $D B C$ solution of the composition $1.6 \mathrm{M} \mathrm{HNO}{ }_{3}-0.038 \mathrm{M}$ $\mathrm{Bi}\left(\mathrm{NO}_{3}\right)_{3}-1.0 \mathrm{Ci}$ per liter 210 Po was contacted at $25,3 \overline{5}$, and $50{ }^{\circ} \mathrm{C}$ with various dilute $\mathrm{HNO}_{3}$ solutions to determine polonium extraction behavior at low $\mathrm{Bi}\left(\mathrm{NO}_{3}\right)_{3}$ concentrations. The DBC solution used in these experiments was prepared by contacting (for $10 \mathrm{~min}$ at $50{ }^{\circ} \mathrm{C}$ ) one volume of $\mathrm{DBC}$, previously adjusted to $1.6 \mathrm{M} \mathrm{HNO}_{3}$ by adding $15.6 \mathrm{M} \mathrm{HNO}_{3}$, with 0.425 volumes of $2.6 \mathrm{M} \mathrm{HNO}_{3}-1.2 \mathrm{M} \mathrm{Bi}\left(\mathrm{NO}_{3}\right)_{3}$ solution containing $2.3 \mathrm{Ci}$ per 
liter of ${ }^{210} \mathrm{Po}$. The transfer of $\mathrm{HNO}_{3}$ occurring in these and most other extraction contacts necessitated analysis of each aqueous phase for $\mathrm{HNO}_{3}$ content. $210 \mathrm{Po}$ in aqueous and $\mathrm{DBC}$ phases obtained in these and a11 other extraction contacts was determined by direct alpha counting of aliquots. Special pains were taken to control temperature during drying of the mounts to prevent volatilization of polonium.

The effects of temperature and aqueous phase composition on equilibrium DBC extraction of $210 \mathrm{Po}$ from $\mathrm{HNO}_{3}-\mathrm{Bi}\left(\mathrm{NO}_{3}\right)_{3}$ solution are well illustrated by the data plotted in Figure 6. Increased temperature depresses ${ }^{210}$ Po extraction in all cases, indicating perhaps an enthalpy effect on the extraction reaction. Maximum extraction of polonium from $1 \mathrm{M} \mathrm{Bi}\left(\mathrm{NO}_{3}\right)_{3}$ solution occurs at about $2.6 \mathrm{M} \mathrm{HNO}_{3}$ while, at low $\mathrm{Bi}\left(\mathrm{NO}_{3}\right)_{3}$ concentration, the maximum distribution ratio is at about $4 \mathrm{M}_{3} \mathrm{HNO}_{3}$. The occurrence of maximum distribution ratios at about these same $\mathrm{HNO}_{3}$ concentrations was noted previously by Sheppard. (9) The position of the maximum polonium $\mathrm{E}_{\mathrm{a}}^{\mathrm{O}}$ appears to depend only on the aqueous phase composition and not on temperature. The $25{ }^{\circ} \mathrm{C}$ distribution data shown in Figure 6 are in excellent agreement with those determined previously by Sheppard ${ }^{(9)}$ at a polonium concentration about $10^{3}$ to $10^{4}$ times lower than the concentration used in this study。

Dibutyl carbitol extraction behavior of polonium(IV) from $\mathrm{HNO}_{3}$ solutions is compared, in Figure 7, with that of certain other quadrivalent metal ions. The data shown for the actinide elements are those reported by McKay and coworkers. (18) The occurrence of a maximum distribution ratio for polonium is an obvious difference. According to Sheppard, $(10)$ the occurrence of the maximum $E_{a}^{O}$ suggests that the charge on the polonium(IV) nitrate complex is zero near 


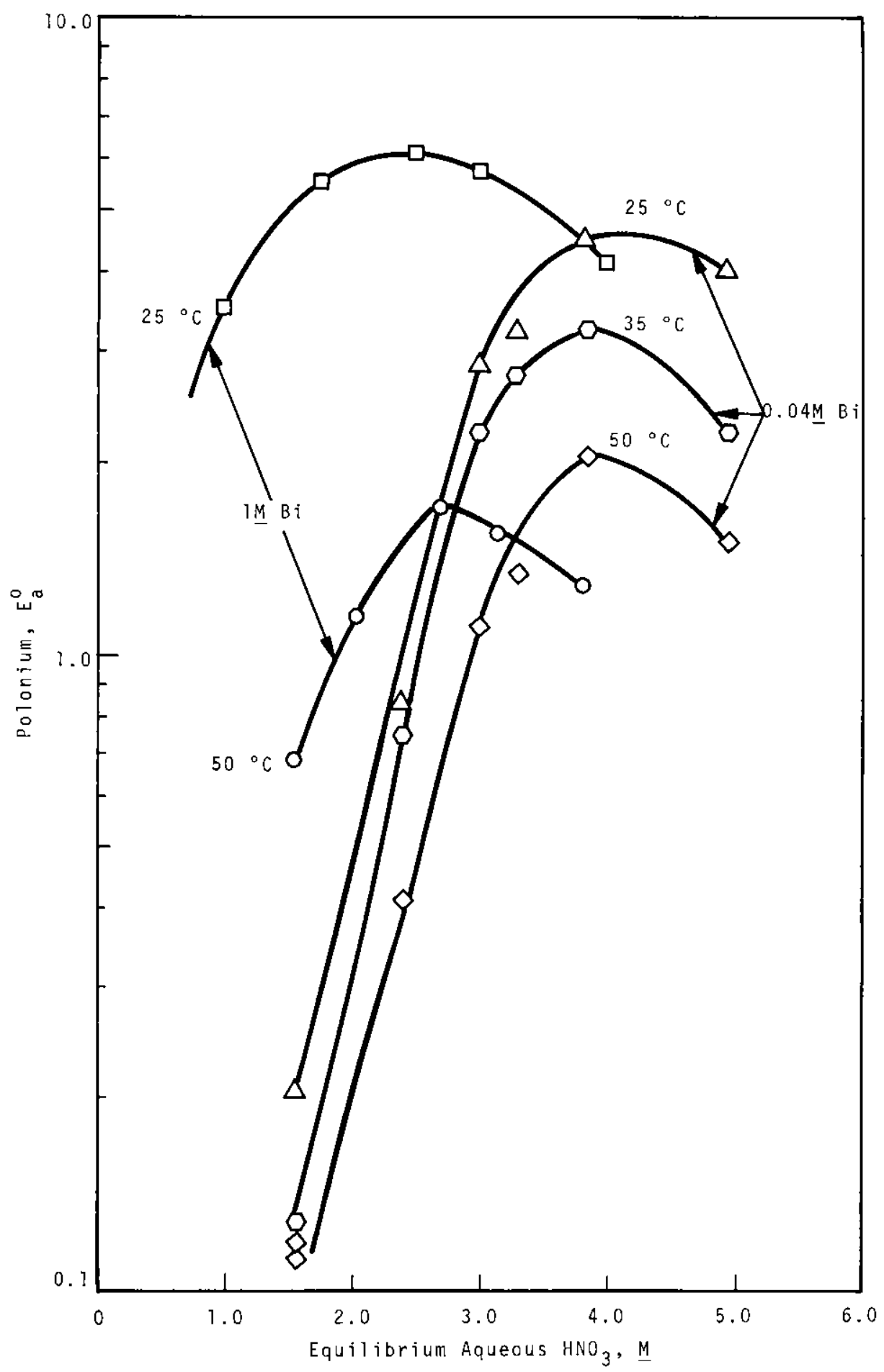

FIGURE 6. Effects of Temperature and Aqueous Phase Composition on DBC Extraction of Polonium 
$4 \mathrm{MNO}_{3}$. It is tempting, therefore, to ascribe the decrease in polonium extraction above $4 \mathrm{M}_{3} \mathrm{HNO}_{3}$ to the formation of anionic nitrate complexes. Surprisingly, however, Pu(IV) and $\mathrm{Np}$ (IV) extraction increases monotonically as a function of $\mathrm{HNO}_{3}$ concentration even at acid concentrations where these actinides are known to form hexanitrato complexes.

Non-Equilibrium Polonium

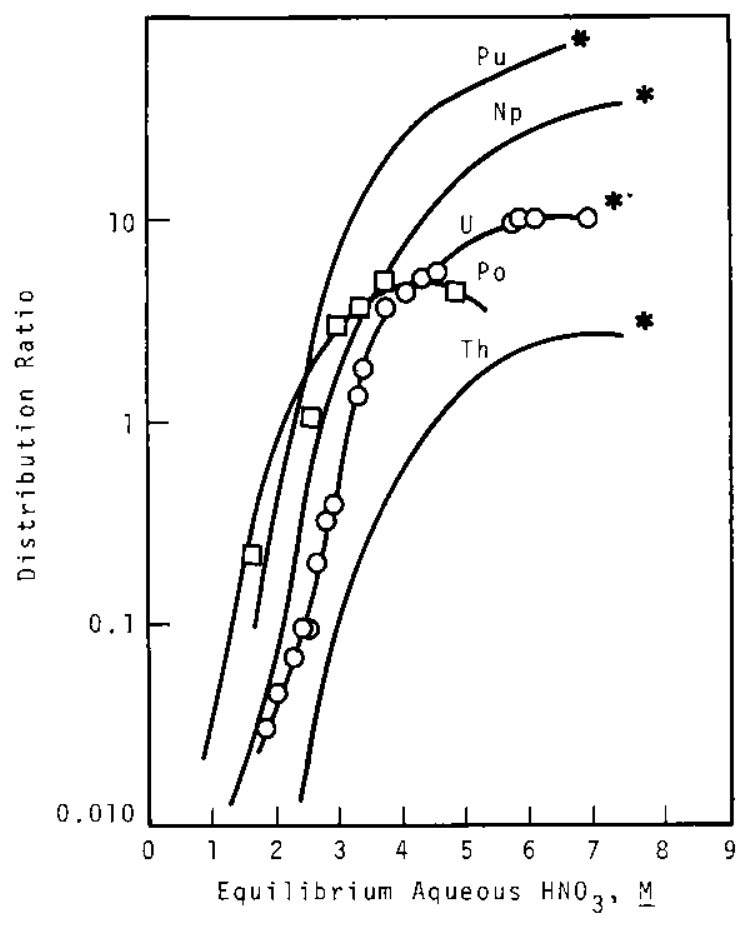

FIGURE 7. DBC Extraction of Polonium and Quadrivalent Actinides from $\mathrm{HNO}_{3}$ Solutions
Extraction. Evidence obtained at several points in this study indicate that the equilibrium polonium specie(s) in aqueous $\mathrm{HNO}_{3}-\mathrm{Bi}\left(\mathrm{NO}_{3}\right)_{3}$ solutions is established only slowly at $25^{\circ} \mathrm{C}$. Typical data illustrating this point are listed in Table V. These distribution data indicate three days or more at $25^{\circ} \mathrm{C}$ are required to establish the equilibrium species. Slow establishment of polonium equilibrium species in $\mathrm{HNO}_{3}$ solutions at $25^{\circ} \mathrm{C}$ has also been reported by Matsuura and coworkers, (7) but at

lower polonium and $\mathrm{HNO}_{3}$ concentrations than used in this work. What may be involved is breaking and reestablishment of oxygen to polonium bonds in a dimeric or polymeric nitrate species.

The polonium distribution data plotted in Figure 8 further demonstrate that the equilibrium polonium species is established slowly at $25^{\circ} \mathrm{C}$. Both sets of data represent $\mathrm{DBC}$ extraction of ${ }^{210} \mathrm{Po}\left(30 \mathrm{~min}\right.$ contact at $\left.25^{\circ} \mathrm{C}\right)$ from 
aqueous $2-6 \underline{\mathrm{M}} \mathrm{HNO}_{3}-1 \mathrm{M} \mathrm{Bi}\left(\mathrm{NO}_{3}\right)_{3}$ solutions containing about $3 \mathrm{Ci}$ per liter of 210 Po. The acid bismuth solutions used in these experiments were prepared by addition of water or $15.6 \mathrm{M} \mathrm{HNO}_{3}$ to a $1 \mathrm{AF}$ solution obtained by $\mathrm{HNO}_{3}$ dissolution of irradiated bismuth metal. The resulting solutions were allowed to stand one week at $25^{\circ} \mathrm{C}$ before contact with $\mathrm{DBC}$ in one case while in another set of experiments the solutions were contacted with DBC within one to two hours after preparation. The shorter standing time was reflected in lower polonium extraction, particularly at the lower $\mathrm{HNO}_{3}$ concentrations.

TABLE V. Time and Temperature Effects on Attainment of Equilibrium Polonium Species

Conditions: A solution of the composition 2.5M $\mathrm{HNO}_{3}-1.23 \mathrm{M}$ $\mathrm{Bi}\left(\mathrm{NO}_{3}\right)_{3}-2.4 \mathrm{Ci} / 1210$ Po was prepared by adding $\mathrm{HNO}_{3}$ to a $2.4 \mathrm{M} \mathrm{HNO}_{3}-1.67 \mathrm{M} \mathrm{Bi}\left(\mathrm{NO}_{3}\right)_{3}-3.4 \mathrm{Ci} / 1210_{\mathrm{PO}}$ solution. Portions of the resulzing solution were stored at both 25 and $50^{\circ} \mathrm{C}$, and, at intervals indicated, were contacted with DBC according to the conditions indicated.

\begin{tabular}{|c|c|c|c|}
\hline & Extraction & at $25{ }^{\circ} \mathrm{C}(\mathrm{a})$ & Extraction at $50{ }^{\circ} \mathrm{C}^{(\mathrm{a})}$ \\
\hline $\begin{array}{l}\text { Hours } \\
\text { Stood } \\
\end{array}$ & $\begin{array}{l}\text { Solution Stored } \\
\text { at } 25^{\circ} \mathrm{C} \\
\text { Po } \mathrm{E}_{\mathrm{a}}^{\circ} \\
\end{array}$ & $\begin{array}{c}\text { Solution Stored } \\
\text { at } 50^{\circ} \mathrm{C} \\
\text { Po } \mathrm{E}^{\circ} \\
\end{array}$ & $\begin{array}{c}\text { Solution Stored } \\
\text { at } 25^{\circ} \mathrm{C} \\
\text { Po } \mathrm{E}^{\circ} \\
\end{array}$ \\
\hline 0.5 & 1.19 & - & 1.79 \\
\hline 1.0 & - & 5.32 & - \\
\hline 5 . & - & 5.43 & - \\
\hline 24. & 1.92 & 5.06 & - \\
\hline 68. & 3.78 & - & - \\
\hline 168. & 6.19 & - & 2.06 \\
\hline 408 & 6.15 & - & - \\
\hline
\end{tabular}

(a) 10 min contact at $A / O=0.425$ with $D B C$ previously adjusted
to $1.6 \underline{\mathrm{MNO}} \mathrm{HO}_{3}$.

The equilibrium polonium species in aqueous $\mathrm{HNO}_{3}$ solutions is attained much more rapidly at $50^{\circ} \mathrm{C}$ than at $25^{\circ} \mathrm{C}$. As is evident from the data in Table $V$, this is true both when the aqueous $\mathrm{HNO}_{3}$ solution is allowed to stand at $50^{\circ} \mathrm{C}$ and then contacted with $\mathrm{DBC}$ at $25^{\circ} \mathrm{C}$, and conversely. 


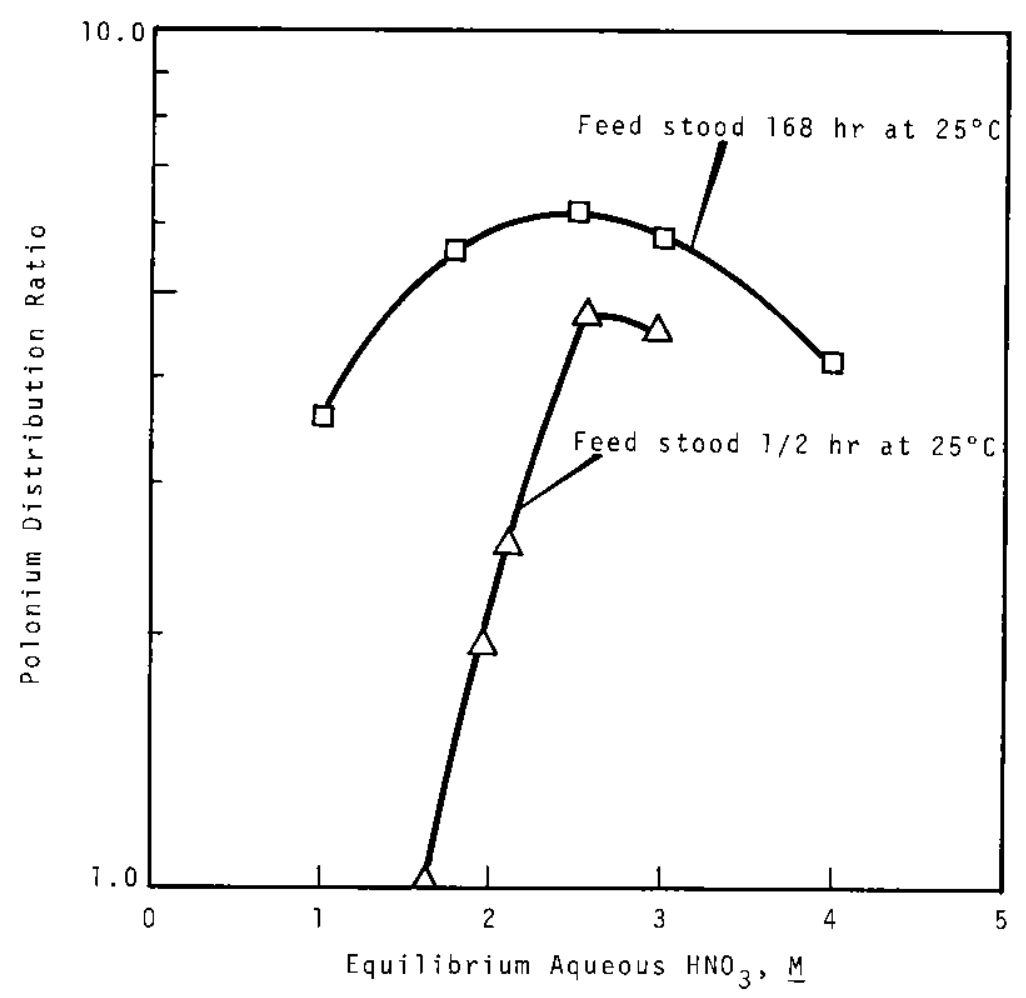

EIGURE 8. Comparison of Equizibrium and Nonequilibrium

Fina11y, in one experiment, a piece of irradiated bismuth metal was dissolved in boiling $7.55 \mathrm{M} \mathrm{HNO}_{3}$ to yield directly without dilution a solution of the composition $2.64 \underline{\mathrm{M}} \mathrm{HNO}_{3}-1.23 \mathrm{M} \mathrm{Bi}\left(\mathrm{NO}_{3}\right)_{3}$. This solution was cooled to $25{ }^{\circ} \mathrm{C}$ and a portion was contacted $\left(30 \mathrm{~min}, 25^{\circ} \mathrm{C}, \mathrm{A} / \mathrm{O}=\right.$ 0.425 ) within 1 to 2 hrs with DBC previously adjusted to $1.6 \mathrm{M} \mathrm{HNO}_{3}$. The ${ }^{210} \mathrm{Po} \mathrm{E}_{\mathrm{a}}^{\circ}$ was 5.64 ; the expected (Figure 6) $E_{a}^{O}$ for extraction of the equilibrium polonium species was 6.1. Thus this experiment gave further proof of the effect of increased temperature in hastening attainment of polonium equilibrium.

Effects of Contact Time on Polonium Extraction. Polonium extracts into $\mathrm{DBC}$ from $1 \mathrm{AFS}$ solution (2.64 $\mathrm{M} \mathrm{HNO}_{3}-1.23$ $\mathrm{Bi}\left(\mathrm{NO}_{3}\right)_{3}-3$ to $\left.4 \mathrm{Ci} /{ }^{210} \mathrm{Po}\right)$ about as fast at $25^{\circ} \mathrm{C}$ as at $50{ }^{\circ} \mathrm{C}$ provided the equilibrium polonium species in the $1 \mathrm{AFS}$ 
solution is first established (Figure 9). However, when the equilibrium polonium species has not been established in the lAFS, then polonium extracts considerably more slowly at 25 than at $50{ }^{\circ} \mathrm{C}$. In the former case, contact time measurements provide information about the transfer rate of the equilibrium extractable polonium species. The transfer rate of this species is as fast at 25 as at $50{ }^{\circ} \mathrm{C}$, attaining the equilibrium $\mathrm{E}_{\mathrm{a}}^{\mathrm{O}}$ at both temperatures in 3 to $5 \mathrm{~min}$ of vigorous agitation. When the equilibrium polonium species have not been established in the lAFS solution, however, contact with a DBC solution provides not only extraction of the extractable polonium species but a means of shifting equilibrium in the aqueous phase toward the formation of the equilibrium extractable species.

Transfer of polonium from the $\mathrm{DBC}$ phase to an aqueous $\mathrm{HNO}_{3}$ solution is also about as fast at 35 as at $50^{\circ} \mathrm{C}$ (Figure 10 ). Just as for transfer in the forward direction, the equilibrium distribution ratio for scrubbing or stripping is attained in 3 to $5 \mathrm{~min}$ of contact.

Care was taken in these contact time studies to use the same mechanical stirring setup and the same stirring speed. The aqueous-to-organic volume ratio was 0.425 in the forward transfer experiments (Figure 9) and was one in the reverse transfer experiments (Figure 10). The DBC solution used in the latter experiments' was prepared by contact $\left(10 \mathrm{~min}, 50{ }^{\circ} \mathrm{C}\right.$, $\mathrm{A} / 0=0.425$ ) of a 1 AFS solution which had stood one week at $25^{\circ} \mathrm{C}$.

Choice of Extraction Column Temperature. The extraction column is designed to operate at $50{ }^{\circ} \mathrm{C}$ in the chemical flowsheet (Figure 2) presently favored for the DBC polonium recovery process. This temperature is specified to ensure reproducible polonium extraction behavior and transfer kinetics commensurate with phase residence times encountered in conventional pulse or packed column equipment. 


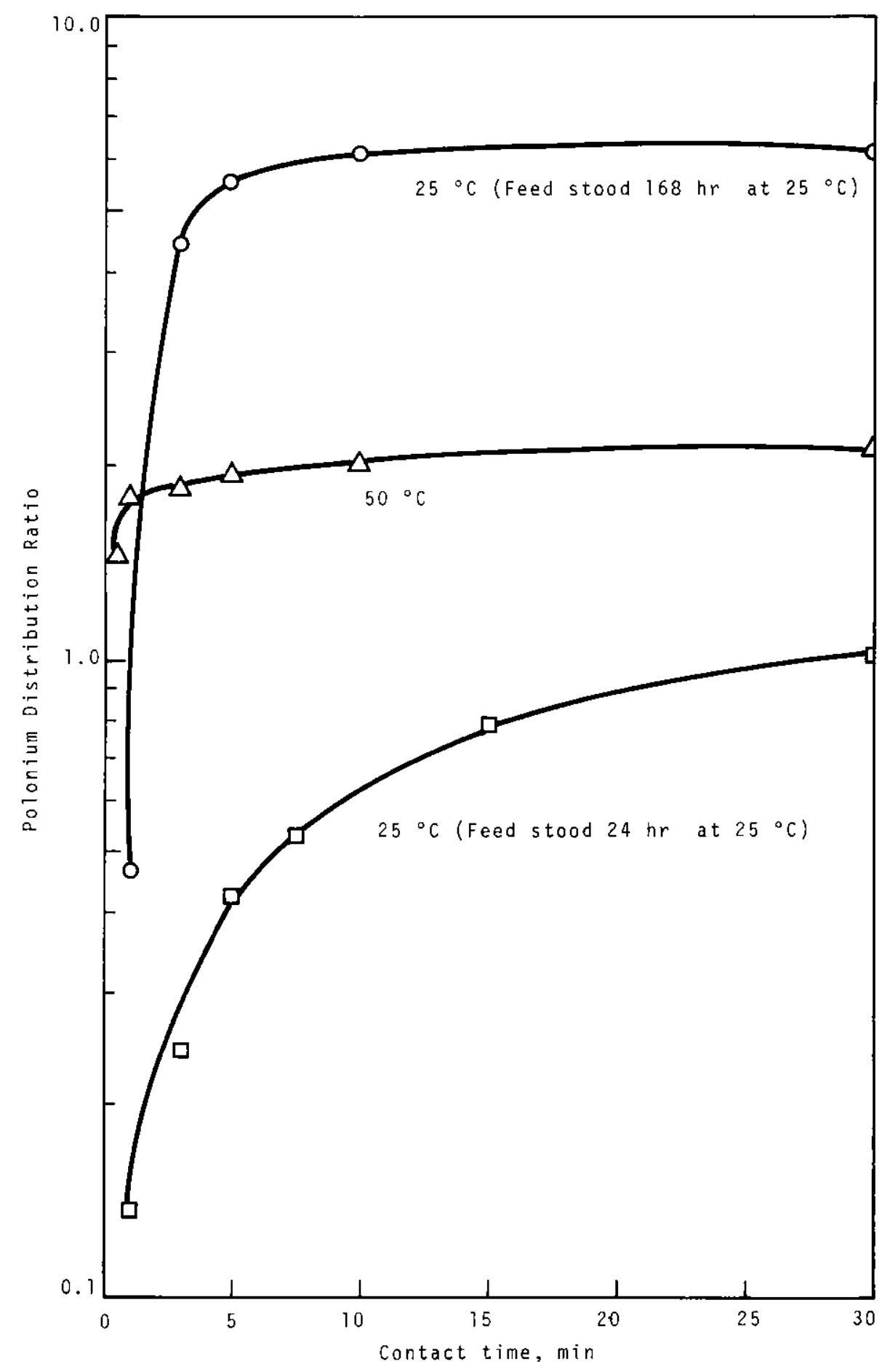

FIGURE 9. Effects of Contact Time on DBC Extraction of Polonium from $\mathrm{HNO}_{3}-\mathrm{Bi}\left(\mathrm{NO}_{3}\right)_{3}$ Solutions 


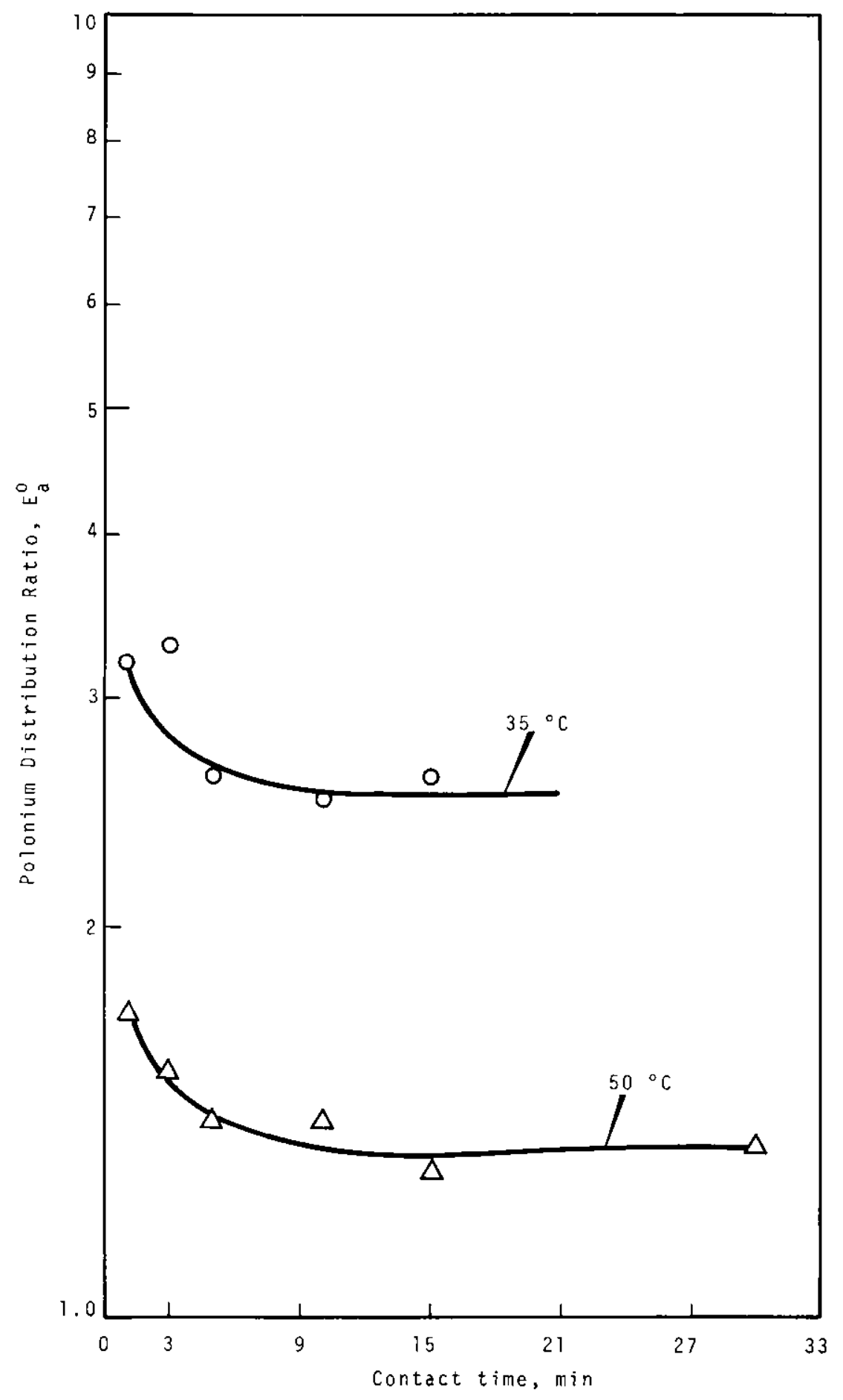

EIGURE 10. Effects of Contact Time on HNO ${ }_{3}$ Stripping
of 210 Po from DBC Solutions 
Results presented in the next two sections amply demonstrate the utility of the $50{ }^{\circ} \mathrm{C}$ extraction column flowsheet. Operation of the extraction column at $50{ }^{\circ} \mathrm{C}$ rather than at $25{ }^{\circ} \mathrm{C}$, however, does have two potential disadvantages. To compensate for the lower polonium distribution ratios at $50{ }^{\circ} \mathrm{C}$ than at $25{ }^{\circ} \mathrm{C}$, a greater organic-to-aqueous flow ratio is required to provide the desired recovery of polonium. Secondly, the chances of nitrite-catalyzed $\mathrm{HNO}_{3}$ degradation of the $\mathrm{DBC}$ are greater at $50^{\circ} \mathrm{C}$, as explained later in this report, than at $25^{\circ} \mathrm{C}$.

The slow rate of attainment of equilibrium polonium species at $25{ }^{\circ} \mathrm{C}$, and the consequences thereof delineated earlier, are naturally a deterrent to operation of the extraction column at $25{ }^{\circ} \mathrm{C}$. A scheme to permit operation at $25{ }^{\circ} \mathrm{C}$ may be simply to digest all entering aqueous polonium streams for an hour or two at $50{ }^{\circ} \mathrm{C}$ before introduction into the extraction column. This concept was not tested in the mixer-settler runs made in this study. It may be feasible, however, in view of the now known effects of temperature on establishment of equilibrium polonium species.

Bismuth and $\mathrm{HNO}_{3}$ Extraction

Distribution of bismuth and $\mathrm{HNO}_{3}$ between $\mathrm{DBC}$ and aqueous solutions of the composition 0.5 or $1 \mathrm{M} \mathrm{Bi(N_{3 } )} 3^{-1}$ to $9 \mathrm{M} \mathrm{HNO}_{3}$ was measured at both 25 and $50{ }^{\circ} \mathrm{C}$. One portion of $\mathrm{DBC}$ was contacted five times at both temperatures with fresh portions of each $\mathrm{Bi}\left(\mathrm{NO}_{3}\right)_{3}-\mathrm{HNO}_{3}$ solution. Concentrations of bismuth and $\mathrm{HNO}_{3}$ in the aqueous and organic phases from the fifth contact, which occurred without volume change, were measured. This technique obviated the large volume changes which occur when $\mathrm{DBC}$ is contacted with an aqueous $\mathrm{HNO}_{3}$ solution, and permitted determination of distribution ratios at essentially constant aqueous phase bismuth concentration. In this latter connection, the volume occupied by $\mathrm{HNO}_{3}$ is about $31 \mathrm{mI}$ per mole of 
$\mathrm{HNO}_{3}$ in the aqueous phase, and about $54 \mathrm{ml}$ per mole of $\mathrm{HNO}_{3}$ in the DBC phase. Nitric acid transfer is thus apparently accompanied by some transfer of water also to account for part of the change in phase volumes on extraction.

Inert bismuth in both aqueous and organic solutions was determined by spectrophotometric determination of the yellow diethyldithiocarbonate complex after extraction into isoamyl alchohol. (19) Nitric acid in aqueous and organic solutions containing bismuth was, after addition of sodium tartrate to complex the bismuth, determined by titration with standard $\mathrm{NaOH}$ to a phenolpthalein end point. This latter titration gives the sum of the $\mathrm{HNO}_{3}$ and bismuth; the $\mathrm{HNO}_{3}$ concentration is found by subtracting twice the bismuth molarity. (20)

At $25{ }^{\circ} \mathrm{C}$, maximum extraction of bismuth into $\mathrm{DBC}$ from aqueous $\mathrm{HNO}_{3}$ solutions occurs at about $4 \mathrm{M}_{-} \mathrm{HNO}_{3}$ (Figure 11 ). Extraction falls off rapidly below this acidity but decreases only slightly over the range 4 to $7 \underline{\mathrm{M}} \mathrm{HNO}_{3}$. Bismuth extracts less at $50{ }^{\circ} \mathrm{C}$ than at $25{ }^{\circ} \mathrm{C}$, and, at both temperatures, extracts less than polonium. At flowsheet (Figure 2) extraction column conditions, $50{ }^{\circ} \mathrm{C}$ and $2.6 \mathrm{M} \mathrm{HNO}_{3}$, the ratio of polonium and bismuth distribution ratios (separation factor) is about 80 .

Experimental data for the distribution of $\mathrm{HNO}_{3}$ between $\mathrm{DBC}$ and aqueous $\mathrm{HNO}_{3}-\mathrm{Bi}\left(\mathrm{NO}_{3}\right)_{3}$ solutions are shown as plotted points in Figure 12. The distribution data at $25{ }^{\circ} \mathrm{C}$ can be correlated fairly well by means of the empirical equation:

$$
\begin{aligned}
\mathrm{HNO}_{3} \mathrm{E}_{\mathrm{a}}^{\mathrm{O}=} & \mathrm{HNO}_{3}\left(\mathrm{E}_{\mathrm{a}}^{\mathrm{O}}\right)_{0.0 \mathrm{M} \mathrm{Bi}}+0.167(\mathrm{M} \mathrm{Bi} \text { in equilibrium } \\
& \text { aqueous phase })
\end{aligned}
$$

This equation was used to draw the full curves shown in Figure 12 for 0.0 to $1.0 \mathrm{M} \mathrm{Bi}\left(\mathrm{NO}_{3}\right)_{3}$ in the aqueous phase. It was also used to estimate $\mathrm{HNO}_{3}$ extraction behavior from 1.5 and $2.0 \mathrm{M} \mathrm{Bi}\left(\mathrm{NO}_{3}\right)_{3}$ solutions. This extrapolation is shown as dashed curves in Figure 12 . 


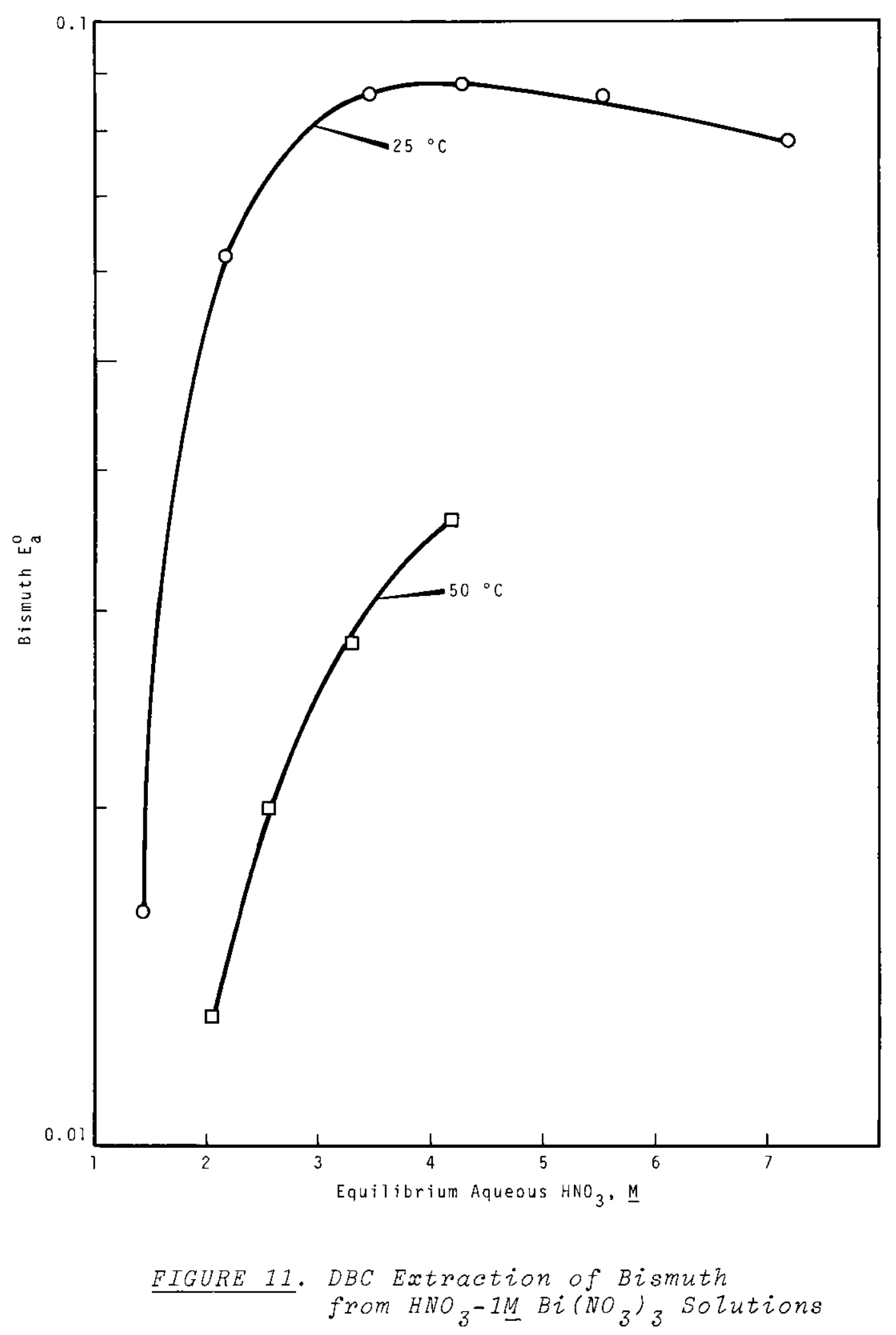




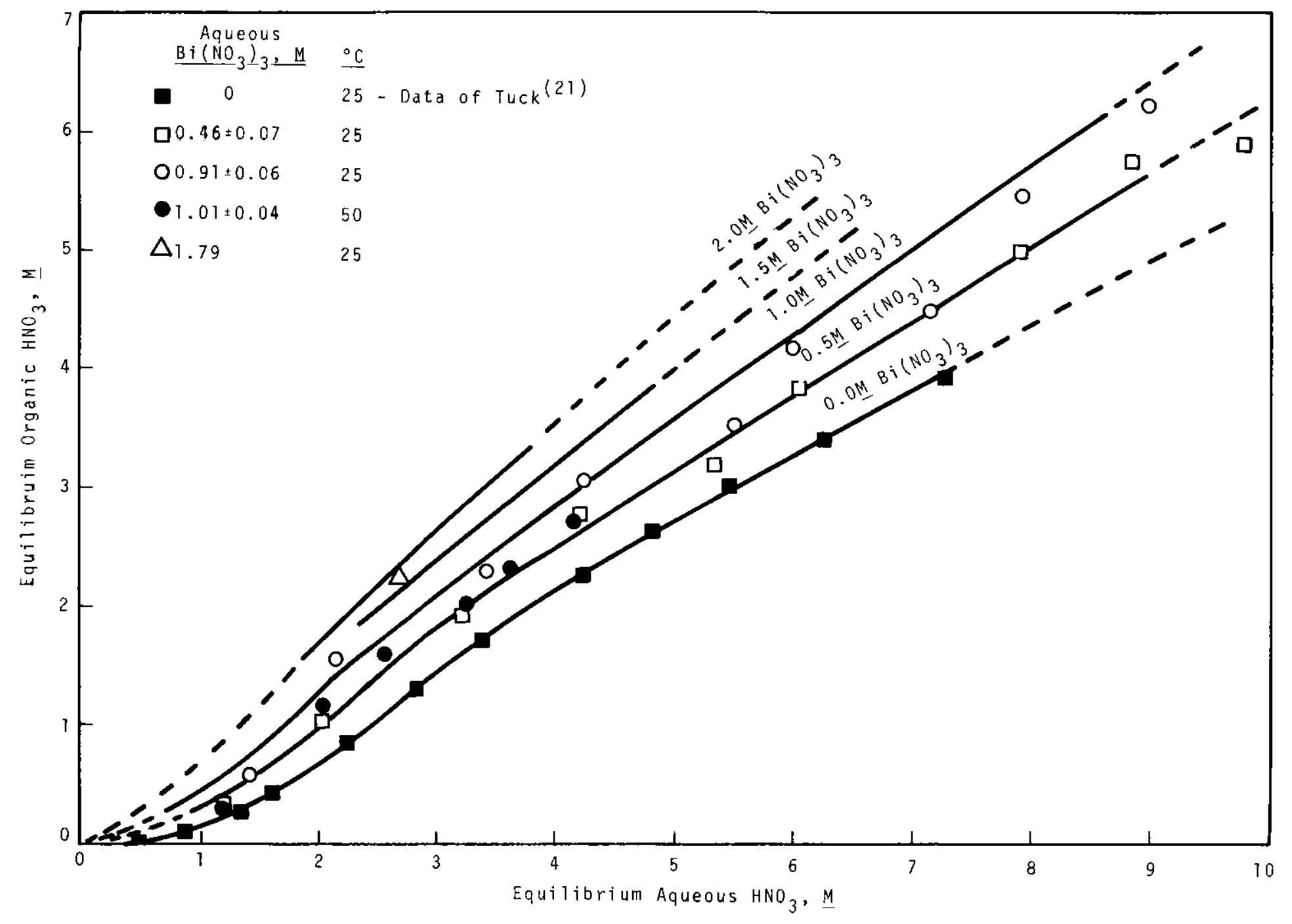

$\stackrel{N}{\infty}$

茎
1
1
0
0

FIGURE 12. DBC Extraction of $\mathrm{HNO}_{3}$ from $\mathrm{HNO}_{3}-\mathrm{Bi}\left(\mathrm{NO}_{3}\right)_{3}$ Solutions 
Mixer-Settler Runs

Tests of the DBC extraction process with feeds containing 210 Po were made in a 12 -stage mixer-settler. This unit was a Hanford designed version of a type developed at the Knolls Atomic Power Laboratory by Coplan and others. (22) Mixing and settling chambers were constructed of flurothene; pump impellers were made of type 304 -L stainless steel; and weirs used to control liquid level were made of glass: ${ }^{210}$ po did not deposit spontaneously on any of these materials. The mixing and settling chambers for this work were embedded in an electrically heated sand bath to permit operation at 35 and $50{ }^{\circ} \mathrm{C}$.

In testing the chemical flowsheet, the mixer-settler was operated with the particular feed, scrub, strip, and organic solution required until a steady state in the effluent streams was reached. Flow rates of aqueous streams were maintained by a syringe-drive system. The $\mathrm{DBC}$, both with and without ${ }^{210}$ Po, was metered to the mixer-settler from an aspirator bottle through a glass flowmeter. Samples of the effluent streams were taken hourly and analyzed to determine when steady state was reached. Polonium losses and bismuth decontamination factors (DF) were computed from analyses of steady state effluent streams. The organic product solutions collected under steady state conditions in the extraction and scrub column runs were used as feed solutions in the succeeding scrub and strip column runs. Except as noted later, mixer-settler runs generally were of 6 to 12 hours duration, and organic solutions containing ${ }^{210}$ Po stood 16 to 24 hours at $25^{\circ} \mathrm{C}$ before use in a scrub or strip column run.

Mixer-settler tests results of the DBC polonium extraction process are summarized in Table VI. The flowsheet conditions shown in Figure 2, except as noted, were used in these runs. The mixer-settler was operated in the majority of runs 
under either simple extraction, simple scrub, or simple strip column conditions. Al1 12 of the mixer-settler stages were used in each of these runs. In two experiments, composite extraction-scrub column runs were made in which the mixersettler was operated at $50{ }^{\circ} \mathrm{C}$ with 7 extraction and 5 scrub stages. Aqueous solutions of the composition $2.6 \mathrm{M} \mathrm{HNO}_{3}-1.23 \mathrm{M}$ $\mathrm{Bi}\left(\mathrm{NO}_{3}\right)_{3}$ and $2.4 \mathrm{M}_{3} \mathrm{HNO}_{3}-1.67 \mathrm{M} \mathrm{Bi}\left(\mathrm{NO}_{3}\right)_{3}$, each containing from 1 to $6 \mathrm{Ci}$ per 1 iter of ${ }^{210} \mathrm{Po}$, were used as feeds in the simple extraction and composite extraction-scrub column runs, respectively. Sulfamic acid was added, in one run of each type, to the extraction column feed and also to the $\mathrm{HNO}_{3}$ scrub solution.

TABLE VI. Mixer-Settier Runs to Demonstrate Polonium Extraction Process

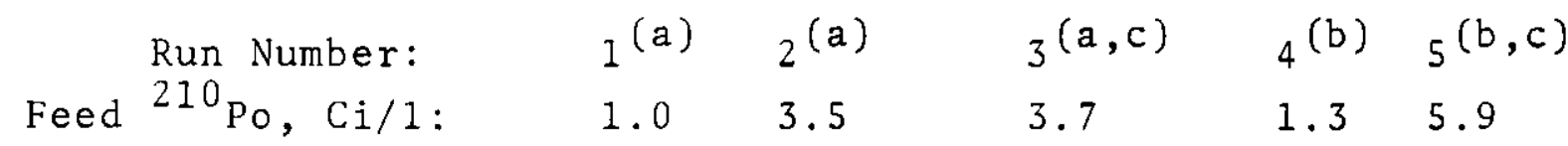

Po Loss, :

Extraction Column:

$0.49 \quad 0.46$

0.61

$1.4 \quad 1.3$

Scrub Column:

4.092 .

4.4

0.45

$0.3 \quad 0.7$

Bismuth DF

Extraction Column:

Scrub Column:

Strip Column:

18
140
1.5

13

14

100

1.2

1250

.5

$1700 \quad 1500$

1.2

Overall: $\quad 3800$

(a) Simple extraction, scrub, and strip column runs.

(b) Composite extraction-scrub column runs.

(c) Feed and scrub contained 0.1 and 0.05 moie per liter sulfamic acid, respectively.

Polonium losses to the aqueous scrub stream were excessively high in Run 2. Otherwise, the mixer-settler runs adequately and successfully demonstrated the utility of the DBC solvent extraction process. Thus, typical ${ }^{210}$ po losses under simple extraction, scrub, and strip column conditions were about $0.5,4$, and $0.4 \%$, respectively. These losses were well within desired 
and specified flowsheet limits. Overall decontamination from bismuth in these runs was also satisfactorily high. Polonium losses were slightly higher and bismuth decontamination was slightly lower in the composite extraction-scrub column runs, corresponding to the fewer extraction and scrub mixer-settler stages employed.

The large polonium loss in the scrub column part of Run 2 was puzzling at first and prompted the detailed studies of solvent degradation discussed subsequently. These studies demonstrated that the excessive polonium losses occurred as the result of a particular kind of chemical degradation of the DBC extractant. For example, the DBC solution used as feed in the scrub column run was found, by distribution ratio measurements, to be almost totally lacking in polonium extraction capacity. Also, the ultraviolet absorption spectrum of the $D B C$ solution demonstrated the presence of organic nitrite compounds. These properties are now known to be characteristic of $D B C$ degraded by $\mathrm{HNO}_{3}$ solutions containing nitrite ion. The extraction column part of Run 2 was atypical in that the mixer-settler was operated only 5 to 6 hours each day for a total of 4 days. The DBC product was allowed to stand during the intervening periods in a closed container, and the mixer-settler was also allowed to stand full of aqueous feed and DBC extractant. These conditions were conducive to nitrite-catalyzed $\mathrm{HNO}_{3}$ attack of the DBC.

Addition of sulfamic acid to feed and scrub solutions is an effective way of preventing nitrite-catalyzed $\mathrm{HNO}_{3}$ attack of the DBC extractant without affecting either recovery or decontamination performance (Runs 3 and 5 ). Sulfamic acid destroys HONO rapidly and efficiently according to the reaction

$$
\mathrm{HONO}+\mathrm{HNH}_{2} \mathrm{SO}_{3} \rightarrow \mathrm{N}_{2}+\mathrm{H}_{2} \mathrm{O}+2 \mathrm{H}^{+}+\mathrm{SO}_{4}^{2-}
$$


Also, in plant operation of the $\mathrm{DBC}$ extraction process, the organic solution from the extraction column would cascade or be pumped to the scrub column without appreciable delay. This situation corresponds to the conditions prevailing in the composite extraction-scrub column mixer-settler runs. These runs proceeded without any evidence of solvent degradation.

Pilot Plant Column Runs

Equipment and Procedures

The pilot plant facility consisted of three 3 -in. diameter glass pulse columns with contacting sections ranging from 9 to $19 \mathrm{ft}$ long. Each column also contained enlarged end sections made in 2 to 3 -ft lengths of 4 -in. diameter glass pipe for phase disengagement. Influent streams were introduced in these enlarged sections within about 2 in. of the contact section, and effluent phases were removed at the extreme ends of the columns. The phase interfaces were also located in the disengaging sections about 8 to 12 inches from the contact section.

Two types of stainless steel nozzle plate cartridges were used. The $1 \mathrm{~A}$ and $1 \mathrm{C}$ columns contained $4-\mathrm{in}$. spaced plates with 3/16-in. diameter holes and $23 \%$ free area. The $1 \mathrm{~B}$ column contained 4-in. spaced plate with $1 / 8-i n$. holes and $10 \%$ free area. The nozzles were indented about 0.04 -in. beyond the face of the plate and were oriented pointing down. In addition, several scouting runs were made with packed columns containing $3 / 4-i n$. stainless steel Raschig rings. Detailed cartridge and packed heights are given in Tables A-2 and A-3 in Appendix A, along with the operating conditions used in each run.

Most of the runs were made at ambient temperature using an early version of the final elevated temperature flowsheet. Run times were generally long enough to approach steady state but, since the runs were of a scouting nature, rigorous proof of 
steady-state was usually not obtained. The columns were usually operated in a cascade series with the solvent phase overflowing from the $1 \mathrm{~A}$ column to the is column, and from the $1 \mathrm{~S}$ column to the $1 \mathrm{C}$ column. Aqueous raffinate from the $1 \mathrm{~s}$ column was continuously pumped back to the top of the lA column to blend with the feed.

Initial feeds for the runs were prepared in the pilot plant dissolver facility. (17) For economy, several feeds were prepared by concentration of raffinates from the $1 \mathrm{~A}$ column and by adjustment of acidity by acid boiloff. Detailed compositions of the feed and other influent streams are presented in Table A-1 in Appendix A.

\section{Pulse Column Run Results}

IA Columns. The maximum capacity demonstrated in the IA column, $920 \mathrm{gal} / \mathrm{hr} \mathrm{ft}^{2}$, was apparently near the limit obtainable with the aqueous phase continuous although considerably higher capacities appeared to be feasible with the organic phase continuous. Considerable variation observed in the instability threshold frequencies may be attributable in part to the recycle of concentrated bismuth raffinate as feed. Detailed run results are shown in Table A-2 in Appendix $A$.

The 1A column extraction efficiency was calculated for Runs 9 and 10 by using uranium as a stand-in for polonium. The uranium HTU's (overall raffinate-film basis)* were estimated to be 1.5 to $1.6 \mathrm{ft}$ with either phase continuous. These results are in line with the excellent quality of the dispersion, which was characterized by uniform, wel1-dispersed 1/16-in. diameter droplets. A conservative uranium distribution ratio of 3 was used in the HTU calculation while the uranium concentration in the feed was about $0.04 \mathrm{M}$.

* HTU refers to the height of a transfer unit; see Reference 23 for a discussion of transfer units, their use, and methods of calculation. 
Acid in the $1 \mathrm{~A}$ column was quite critically controlled to avoid bismuth subnitrate precipitation. This control was achieved by adding $1 \mathrm{M}^{\mathrm{H} O} \mathrm{H}_{3}$ to the $\mathrm{DBC}$ extractant. Acid-free DBC could be used safely at steady-state provided that the flowsheet was properly designed to avoid excessive extraction of $\mathrm{HNO}_{3}$.

IS Column. The flooding capacity of the $1 \mathrm{~s}$ column, using the $10 \%$ free-area cartridge, was the lowest obtained in these studies. With the aqueous phase continuous, the maximum stable capacity was only slightly greater than the highest volume velocity demonstrated ( $590 \mathrm{gal} / \mathrm{hr} \mathrm{ft}^{2}$, sum of flows). Somewhat higher capacities were indicated by the frequencies attainable with the solvent phase continuous. Still higher capacities should be obtained with the same $23 \%$ free-area cartridge used in the other columns.

The primary efficiency of the $1 \mathrm{~s}$ column was measured by the bismuth decontamination factors. These ranged from 230 to 920 (HTU's of 1.5 to $1.9 \mathrm{ft}$ ) with 0.1 to $0.2 \mathrm{M} \mathrm{HNO} 3$ in the scrub stream to 1900 to 3300 (HTU's of 1.3 and $1.4 \mathrm{ft}$ ) with $1 \mathrm{M} \mathrm{HNO}_{3}$ scrub. Insufficient runs were made to confirm the apparent improvement in efficiency with the higher acid scrubs.

Uranium and $\mathrm{HNO}_{3} \mathrm{HTU}$ 's were also determined for several of the runs. Apparent uranium HTU's of 1 and $1.1 \mathrm{ft}$ were obtained in conjunction with $1 \mathrm{~A}$ column tests previously described, while $\mathrm{HNO}_{3} \mathrm{HTU}^{\prime} \mathrm{s}$ appeared to be about the same as the bismuth values.

1C Column. The 1C column proved to be highly stable. Vo1ume velocities as high as $1600 \mathrm{gal} / \mathrm{hr} \mathrm{ft}^{2}$ were readily obtained with the aqueous phase continuous, and higher capacities appeared to be possible. The high rate runs were often characterized by cyclic buildings of the dispersed organic phase, followed by coalescence and channeling of large organic droplets 
to the top. At all times, the dispersion in the $1 \mathrm{C}$ column had a very frothy appearance due to the wide range of drop sizes $(<1 / 16$ to $1 / 4 \mathrm{in.})$. This type of performance is typical of coalescing systems. Large drops do not necessarily lead to poor extraction performance in such systems because of the constantly renewed surfaces produced by coalescence and redispersion.

Both bismuth and $\mathrm{HNO}_{3} \mathrm{HTU}^{\prime} \mathrm{s}$ were used to determine the efficiency of the $1 C$ column. The most representative values were in the range of 1.2 to $1.7 \mathrm{ft}$ at a volume velocity of $550 \mathrm{gal} / \mathrm{hr} \mathrm{ft}{ }^{2}$ and 1.6 to $2.6 \mathrm{ft}$ at $1550 \mathrm{gal} / \mathrm{hr} \mathrm{ft}^{2}$.

Packed Column Studies

A series of packed column runs was made to determine the feasibility of installing the $D B C$ process in the Hanford Redox Plant, a recently deactivated solvent extraction plant used to purify uranium and plutonium by hexone extractions in packed columns. The results are presented in Table $\mathrm{A}-3$.

The runs demonstrated that stable volume velocities as high as 2000,1360 , and $1610 \mathrm{gal}^{\mathrm{hr} \mathrm{ft}^{2}}$ were obtainable in the $1 \mathrm{~A}, 1 \mathrm{~S}$, and $1 \mathrm{C}$ columns, respectively, at $50^{\circ} \mathrm{C}$. Capacities were about $10 \%$ lower at $25{ }^{\circ} \mathrm{C}$.

The quality of the dispersion was excellent in the $1 \mathrm{~A}$ column over a volume velocity range of 500 to $2000 \mathrm{gal} / \mathrm{hr} \mathrm{ft}^{2}$. The 1S column had a fairly good dispersion in all but the top third of the column. The $1 \mathrm{C}$ column had a very coarse dispersion throughout. With the notable exception of the 1A column, the performance generally obtained with the packed columns was visually inferior to that obtained with the pulse columns. This evaluation was confirmed by bismuth and $\mathrm{HNO}_{3}$ HTU's obtained for the $1 \mathrm{~S}$ and $1 \mathrm{C}$ column. These were typically about twofold higher than the HTU's obtained in the pulse column runs described 
earlier. Adding pulse energy lowered the IC column HTU slightly, though not as much as might be inferred from the improvement in dispersion.

Two 1 o-column tests were also made using $5 \% \mathrm{Na}_{2} \mathrm{CO}_{3}$ to scrub $\mathrm{HNO}_{3}$ and impurities from the solvent. The capacity was about half that obtained in the other columns and was about $20 \%$ higher at $48^{\circ} \mathrm{C}$ than at room temperature. A good dispersion was obtained, and scrubbing performance was apparently adequate.

Solvent Degradation Effects

Reaction of $\mathrm{DBC}$ with $\mathrm{HNO}_{3}$ at 25 and $500^{\circ} \mathrm{C}$

As stated earlier, the high polonium loss noted in one of the mixer-settler scrub column runs prompted detailed studies of the effects and consequences of solvent degradation on polonium extraction capacity. In initial studies, DBC was equilibrated at $25^{\circ} \mathrm{C}$ with $15.6 \mathrm{M} \mathrm{HNO}_{3}$ to yield an organic solution of 0.5 to $2.0 \mathrm{M} \mathrm{HNO}_{3}$. Portions of the resulting organic solution were placed in tightly stoppered containers and maintained at $50{ }^{\circ} \mathrm{C}$ for periods of time ranging from 3 to 96 hours. Each organic solution was cooled at appropriate times to $25^{\circ} \mathrm{C}$, titrated for $\mathrm{HNO}_{3}$ concentration, washed with an equal volume of water, and readjusted to $1.6 \mathrm{M} \mathrm{HNO}_{3}$. The polonium extraction capacity of the resulting organic solution was measured by contact $\left(10 \mathrm{~min}, 50^{\circ} \mathrm{C}, \mathrm{A} / \mathrm{O}=1 / 2.35\right)$ with 1 AFS solution. Results of these experiments are tabulated in Table VII.

In similar studies, $\mathrm{DBC}$ was adjusted to $1.64 \underline{\mathrm{M}} \mathrm{HNO}_{3}$ and contacted $\left(10 \mathrm{~min}, 50^{\circ} \mathrm{C}, \mathrm{A} / \mathrm{O}=0.425\right)$ with $1 \mathrm{AFS}$ solution to produce an organic phase about $1.6 \underline{\mathrm{M}} \mathrm{HNO}_{3}$ and $0.04 \underline{\mathrm{M}} \mathrm{Bi}\left(\mathrm{NO}_{3}\right)_{3}$ and containing about $1.0 \mathrm{Ci}$ per 1 iter of ${ }^{3}{ }^{2}$ Po. This organic solution was allowed to stand 336 hours at $25^{\circ} \mathrm{C}$. Portions of this organic phase were removed at certain selected intervals and 
contacted $\left(30 \mathrm{~min} 35^{\circ} \mathrm{C}, \mathrm{A} / \mathrm{O}=1\right)$ with $3.4 \underline{\mathrm{M}} \mathrm{HNO}_{3}$ to determine polonium extraction capacity. Results of this test are given in Table VIII.

$$
\begin{aligned}
& \text { TABLE VII. Effects on Polonium Extraction Capacity } \\
& \text { of Storing DEC-HNO } 3 \text { Solutions at } 50{ }^{\circ} \mathrm{C}
\end{aligned}
$$

Conditions: As described in text.

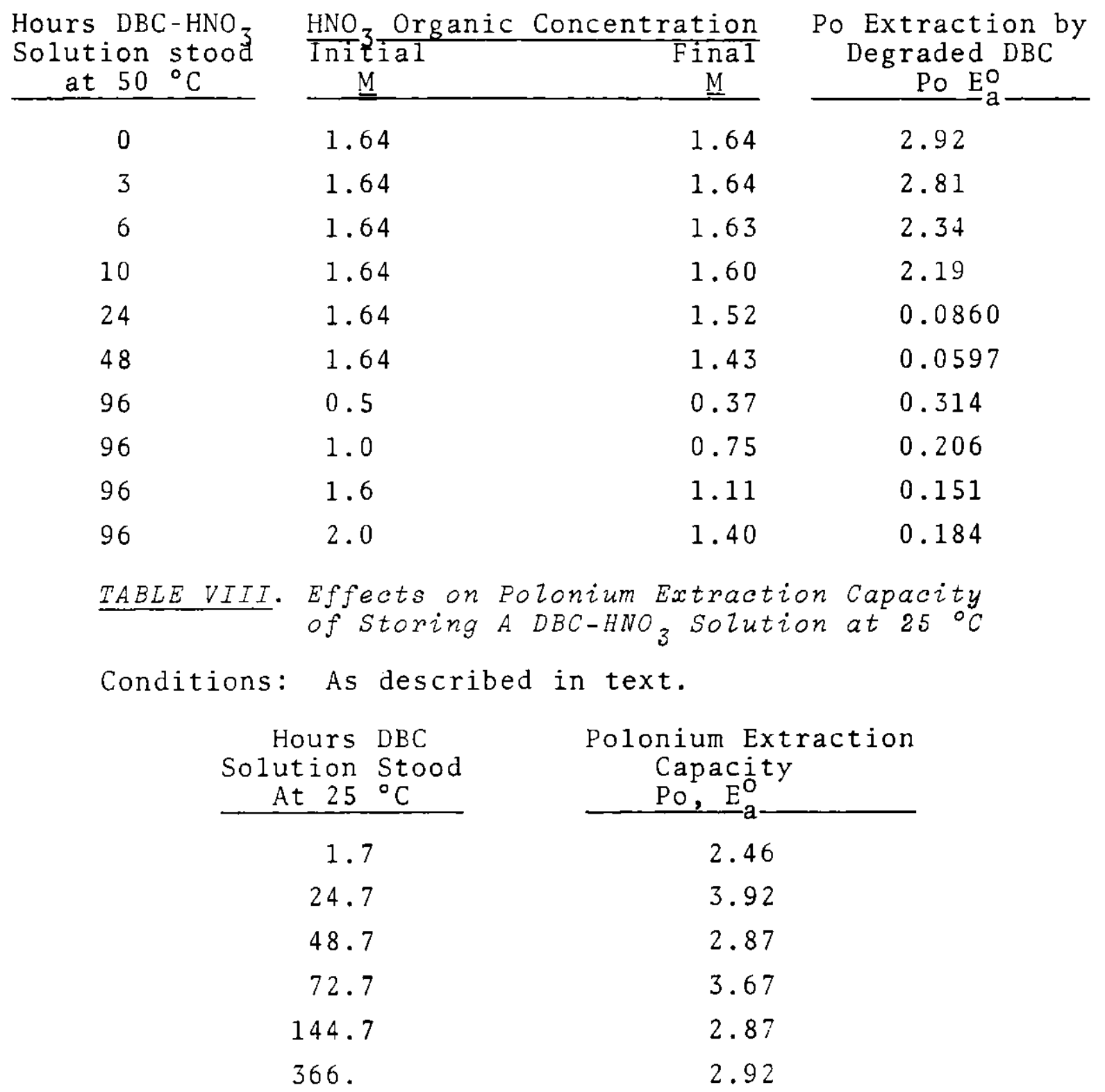


Little or no loss in polonium extraction capacity occurred when the $\mathrm{DBC}-\mathrm{HNO}_{3}$ solution was allowed to stand two weeks at $25^{\circ} \mathrm{C}$. However, some reaction occurred in $\mathrm{DBC}-\mathrm{HNO}_{3}$ solutions allowed to stand for 24 hours or longer at $50^{\circ} \mathrm{C}$ in sealed containers which resulted in destruction of $\mathrm{HNO}_{3}$ and loss of polonium extraction capacity. The extent of this reaction depended, as would be expected, on reaction time and initial $\mathrm{HNO}_{3}$ concentration.

No gross destruction of $\mathrm{DBC}$ was disclosed by gas chromatographic and infrared analyses when $\mathrm{DBC} \cdot \mathrm{HNO}_{3}$ solutions were allowed to stand at $50{ }^{\circ} \mathrm{C}$. Thls finding was supported by the fact that all the water-washed, degraded DBC solutions extracted $\mathrm{HNO}_{3}$ about as well as "as-recelved" material. These results thus showed that the loss in polonium extraction capacity could not be attributed simply to destruction of $\mathrm{DBC}$ by the $\mathrm{HNO}_{3}$. Rather, consideration of the results of Susano(14) on the role of nitrite lon in attack of $\mathrm{DBC}$ by $\mathrm{HNO}_{3}$ suggested that nitrite ion could also be involved in some way with loss of polonium extraction capacity and led to the studies reported in the section immediately following.

Degradation of DBC by ${ }_{\text {HNO }}-$ NaNO $_{2}$ Solutions

The polonium extraction capacity of $\mathrm{DBC}$ decreases markedly when it is contacted at $50{ }^{\circ} \mathrm{C}$ with aqueous $\mathrm{HNO}_{3}{ }^{-\mathrm{NaNO}_{2}}$ solutions (Table $I X)$. Even in the absence of added nitrite, a similar decrease in polonium distribution ratio results when the aqueous $\mathrm{HNO}_{3}$ solution contains 0.5 (or more) $\mathrm{Ci}$ per liter of ${ }^{210} \mathrm{Po}$. In either case, addition of sulfamic acid or hydrazine to the aqueour phase before contact with the organic solution prevents degradation of the $D B C$ extractant.

Peaks characteristic of nitrite compounds (24) were plain1y evident in the ultraviolet absorption spectra of all the degraded (Table IX) DBC solutions. The adverse effect of nitrites 
TABLEIX. Degradation of $D B C$ by $\mathrm{HNO}_{3} \mathrm{NO}_{2}^{-}$Solutions

Conditions: $\quad$ BBC stirred for time indicated at $50{ }^{\circ} \mathrm{C}$ with equal volume of indicated aqueous solution. Resulting organic phase cooled to $25^{\circ} \mathrm{C}$, washed with an equal volume of water, and adjusted to $1.6 \mathrm{M} \mathrm{HNO}_{3}$ by addition of $15.6 \mathrm{M} \mathrm{HNO}_{3}$. The resulting organic solution was then contacted ( $10 \mathrm{~min}$, $50^{\circ} \overline{\mathrm{C}}, \mathrm{A} / \mathrm{O}=0.425$ ) with lAFS solution.

\begin{tabular}{|c|c|c|c|c|c|c|}
\hline $\begin{array}{c}\mathrm{NaNO}_{2} \\
-\mathrm{M} \\
\end{array}$ & $\begin{array}{l}\text { Sulfamic } \\
\text { Acid } \\
\underline{M}\end{array}$ & $\begin{array}{c}\text { Hydrazine } \\
\end{array}$ & $\begin{array}{c}\mathrm{Bi}\left(\mathrm{NO}_{3}\right)_{3} \\
\underline{\underline{M}}\end{array}$ & $\begin{array}{l}210 \mathrm{Po} \\
\mathrm{Ci} / 1 \\
\end{array}$ & $\begin{array}{l}\text { Time at } \\
50{ }^{\circ} \mathrm{C} \\
\text { hrs } \\
\end{array}$ & $\begin{array}{c}\text { Polonium Extraction } \\
\text { Capacity of Degraded DBC } \\
\text { Po } \mathrm{E}_{\mathrm{a}}^{\circ}\end{array}$ \\
\hline 0.0 & 0.0 & 0.0 & 0.0 & 0.0 & 48 & 1.87 \\
\hline 0.005 & 0.0 & 0.0 & 0.0 & 0.0 & 48 & 1.91 \\
\hline 0.01 & 0.0 & 0.0 & 0.0 & 0.0 & 48 & 2.00 \\
\hline 0.015 & 0.0 & 0.0 & 0.0 & 0.0 & 48 & 0.0419 \\
\hline 0.020 & 0.0 & 0.0 & 0.0 & 0.0 & 48 & 0.0408 \\
\hline 0.025 & 0.0 & 0.0 & 0.0 & 0.0 & 48 & 0.0263 \\
\hline 0.05 & 0.0 & 0.0 & 0.0 & 0.0 & 6 & 0.0184 \\
\hline 0.05 & 0.0 & 0.0 & 0.0 & 0.0 & 17 & 0.0344 \\
\hline 0.05 & 0.0 & 0.0 & 0.0 & 0.0 & 48 & 0.0170 \\
\hline 0.10 & 0.0 & 0.0 & 0.0 & 0.0 & 48 & 0.0157 \\
\hline 0.0 & 0.0 & 0.0 & 1.62 & 0.54 & 48 & 0.0160 \\
\hline 0.0 & 0.0 & 0.0 & 1.62 & 6.0 & 24 & 0.207 \\
\hline 0.025 & 0.05 & 0.0 & 0.0 & 0.0 & 48 & 1.49 \\
\hline 0.025 & 0.0 & 0.025 & 0.0 & 0.0 & 48 & 1.55 \\
\hline 0.025 & 0.0 & 0.05 & 0.0 & 0.0 & 48 & 1.74 \\
\hline 0.05 & 0.1 & 0.0 & 0.0 & 0.0 & 17 & 1.69 \\
\hline 0.0 & 0.1 & 0.0 & 1.62 & 0.54 & 48 & 1.63 \\
\hline 0.0 & 0.05 & 0.0 & 1.62 & 6.0 & 24 & 1.62 \\
\hline 0.0 & 0.10 & 0.0 & 1.62 & 6.0 & 24 & 1.74 \\
\hline 0.0 & 0.0 & 0.1 & 1.62 & 6.0 & 24 & 1.24 \\
\hline
\end{tabular}

(a) All solutions also contain 2.6 moles per liter of $\mathrm{HNO}_{3}$. 
on extraction of ${ }^{210}$ Po by DBC was also noted when either octyl or butyl nitrite was added to "as-received" DBC (Table X). Adding either nitrooctane or octy 1 nitrate, however, did not affect polonium extraction. While the reaction mechanism responsible for the deleterious effect of nitrites on polonium extraction is not known, reduction of Po(IV) to Po(II) in the organic phase may be involved. Alternatively, some aqueousfavoring complex between nitrites and Po(IV) may be formed.

\section{TABLEX. Effect of Organic Nitrogen Compounds on $D B C$ Extraction of PoZonium}

Conditions: $\quad$ B BC solutions containing indicated organic nitrogen compounds were adjusted to $1.6 \mathrm{M} \mathrm{HNO}_{3}$ by addition of $15.6 \mathrm{M} \mathrm{HNO}_{3}$ and then contacted $(10 \mathrm{~min}$, $50{ }^{\circ} \mathrm{C}, \mathrm{A} / \mathrm{O}=0.4 \overline{2} 5$ ) with lAFS solution.

Organic Nitrogen Compound

Type $\quad \underline{\text { Vol\% }} \quad$ Po E $\mathrm{E}_{\mathrm{a}}^{\mathrm{O}}$

Butyl Nitrite

1

0.326

Octyl Nitrite

$5 \quad 0.104$

Octyl Nitrite

10.238

Octy1 Nitrate

$5 \quad 0.0749$

Nitrooctane

1.72

$1 \quad 1.74$

Significantly, contact of the DBC extractant with aqueous $\mathrm{HNO}_{3}-\mathrm{NaNO}_{2}$ solutions at $50{ }^{\circ} \mathrm{C}$ did not impair the capacity of the $\mathrm{DBC}$ to extract $\mathrm{HNO}_{3}$. Furthermore, gas chromatographic and infrared analyses of the degraded DBC solvents indicated 1ittle, if any, destruction of the $\mathrm{DBC}$ itself. The degradation conditions employed and encountered in this work were only sufficient, apparently, to produce small amounts of unidentified organic nitrite compounds which interfere with extraction of $10^{-6}$ to $10^{-5} \underline{M}$ polonium. Presumably, prolonged contact of $\mathrm{DBC}$ at $50{ }^{\circ} \mathrm{C}$ with $\mathrm{HNO}_{3}$ solutions conatining nitrite would lead to the degree and kind of degradation observed by Susano, (14) but such exposure is beyond that expected in operation of the polonium extraction process. 
Nitrite is known to be one of the radiolysis products of aqueous polonium nitrate solutions. (25) Radiolyticallygenerated nitrite presumably brings about the solvent degradation which occurs when DBC is contacted at $50{ }^{\circ} \mathrm{C}$ with $\mathrm{HNO}_{3}$ solutions containing ${ }^{210}$ Po. British workers, ${ }^{(11)}$ in their investigation of the reaction between $\mathrm{DBC}$ and $\mathrm{HNO}_{3}$, noted that beta and gamma radiation triggers off a reaction indistinguishable from the thermal reaction.

Precipitation of Solids from Degraded DBC Solutions

Black solids were precipitated from lAP solutions produced in the various mixer-settler runs when such $D B C$ solutions were allowed to stand for about two weeks in closed containers. A portion of these solids, isolated, washed with water and acetone, and air-dried, were found to contain $69.0 \mathrm{wt} \%$ bismuth and considerable amounts of ${ }^{210}$ Po.

The identity of the black solids has not been established. Their x-ray powder pattern does not correspond to any of those described in the American Society for Testing Materials (ASTM) card file, nor are these solids indicated by differential thermal analysis to be $\mathrm{BiONO}_{3} \cdot \mathrm{H}_{2} \mathrm{O}$. It seems likely, however, that they are some hydrolysis product precipitated when $\mathrm{HNO}_{3}$ in the DBC solution is destroyed. The black color presumably arises from the color centers produced by the intense alpha radiation from the ${ }^{210}$ Po present.

White solids containing 64.4 wt: bismuth and having the same (Table B-1, Appendix B) x-ray powder diffraction pattern as the black solids were prepared in the absence of polonium by the following procedure. As-received $\mathrm{DBC}$ was adjusted to $1.6 \mathrm{M}$ $\mathrm{HNO}_{3}$ by addition of $15.6 \mathrm{M} \mathrm{HNO}_{3}$ and then contacted (10 min, $50{ }^{\circ} \mathrm{C}, \mathrm{A} / \mathrm{O}=0.425$ ) with synthetic (no ${ }^{210} \mathrm{Po}$ ) lAFS solution. The resulting organic solution was held (in a pot open to the air) at $50{ }^{\circ} \mathrm{C}$ for 100 hours without precipitation of solids. 
At this point solid $\mathrm{NaNO}_{2}$ was added to the organic solution to make it about $0.1 \mathrm{M}$ in nitrite. Large amounts of white solids precipitated within about 10 hours.

Solvent Washing. Techniques

The used DBC extractant from the strip column will contain small amounts of polonium, bismuth, and $\mathrm{HNO}_{3}$, These contaminants can be removed by routine washing of the solvent with a dilute $\mathrm{Na}_{2} \mathrm{CO}_{3}$ or $\mathrm{NaOH}$ solution (Table XI).

However, alkaline washes do not restore the polonium extraction capacity of $\mathrm{DBC}$ degraded by exposure to $\mathrm{HNO}_{3}-\mathrm{NaNO}_{2}$ solutions. For this purpose, $\mathrm{HNO}_{3}-\mathrm{KMnO}_{4}$ washes are very effective as illustrated by the results shown in Table XII. Spectrophotometric and chromatographic analyses indicate the $\mathrm{KMnO}_{4}$ oxidizes the organic nitrites in the degraded DBC to innocuous species without any appreciable attack on the DBC.

\section{TABLEXI. AZkaline Washes of Degraded DBC}

Conditions: Degraded $\mathrm{DBC}\left(48 \mathrm{hrs}\right.$ at $50^{\circ} \mathrm{C}$ with equal volume of $2.6 \mathrm{M} \mathrm{HNO}_{3}-0.1 \mathrm{M} \mathrm{NaNO}_{2}$ ) washed twice with water. Portions of résulting material washed (10 min, $25^{\circ} \mathrm{C}, \mathrm{A} / \mathrm{O}=1$ ) with alkaline washes indicated. Finally, the washed $\mathrm{DBC}$ was adjusted to $1.6 \mathrm{M} \mathrm{HNO}_{3}$ and contacted $\left(10 \mathrm{~min}, 50{ }^{\circ} \mathrm{C}, \mathrm{A} / \mathrm{O}=1 / 2.35\right)^{-}$with $^{3}$ lAFS solution to determine polonium extraction capacity.

Wash Composition

$3 \% \mathrm{Na}_{2} \mathrm{CO}_{3}$

$1 \mathrm{M} \mathrm{NaOH}$

None (a)

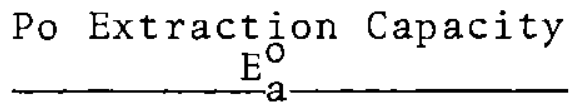

0.0348

0.0446

0.0157

(a) Water washes only. 
TABLE XII. Washing of Degraded $\mathrm{DBC}$ with $\mathrm{HNO}_{3}-\mathrm{KMnO}_{4}$ Solutions Conditions: $D B C$ from sources indicated were contacted 60 min at $25{ }^{\circ} \mathrm{C}$ with an equal volume of $2 \mathrm{M} \mathrm{HNO}_{3}-0.0$ to $0.2 \mathrm{M} \mathrm{KMnO}_{4}$ solution. Without phas $\overline{\mathrm{e}}$ separation, the aqueous phase was made $0.2 \mathrm{M}$ oxalic acid and phases were mixed $10 \mathrm{~min}$ at $50^{\circ} \mathrm{C}$. Resulting organic solution was washed twice with water ( $10 \mathrm{~min}, 25{ }^{\circ} \mathrm{C}, \mathrm{A} / \mathrm{O}=1$ ), adjusted to $1.6 \mathrm{M} \mathrm{HNO}_{3}$, and contacted $\left(10 \mathrm{~min}, 50^{\circ} \mathrm{C}, \mathrm{A} / 0=1 / 2.3 \overline{5}\right)$ with 1 AFS solution.

\begin{tabular}{|c|c|c|}
\hline Organic Code ${ }^{(a)}$ & $\begin{array}{l}\mathrm{KMnO}_{4} \\
\underline{\underline{\mathrm{M}}} \\
\end{array}$ & $\begin{array}{c}\text { Polonium, } \\
E_{2}^{0}\end{array}$ \\
\hline$A^{(b)}$ & - & 1.74 \\
\hline $\mathrm{B}^{(\mathrm{b})}$ & - & 0.134 \\
\hline B & 0.1 & 1.52 \\
\hline B & 0.2 & 1.53 \\
\hline$C^{(b)}$ & - & 0.238 \\
\hline $\mathrm{C}$ & 0.2 & 1.34 \\
\hline D & 0.0 & 0.0238 \\
\hline D & 0.05 & 0.0666 \\
\hline $\mathrm{D}$ & 0.10 & 0.035 \\
\hline $\mathrm{D}$ & 0.15 & 0.366 \\
\hline D & 0.20 & 1.54 \\
\hline
\end{tabular}

(a) A As-received $D B C$

$B$ Degraded $D B C$ from mixer-settier Run 2, Table VI

$C$ As-received $D B C$ containing 1 vol\% octyl nitrite.

$D$ Chemically degraded $\left(48 \mathrm{hr}\right.$ contact at $50^{\circ} \mathrm{C}$ with equal volume of $2.6 \underline{\mathrm{M}} \mathrm{HNO}_{3}-0.1 \mathrm{M} \mathrm{NaNO}_{2}$ ) $\mathrm{DBC}$

(b) Not washed.

Manganese dioxide, which precipitates when degraded $D B C$ is contacted with a $\mathrm{HNO}_{3}-\mathrm{KMnO}_{4}$ solution, accumulates at the organic-aqueous interface and makes phase separation difficult. A convenient way to circumvent this problem is to add oxalic acid to the aqueous phase before attempting phase separation. The oxalic acid reacts with, and dissolves, the $\mathrm{MnO}_{2}$ without negating the beneficial effects of the acid $\mathrm{KMnO}_{4}$ wash on polonium extraction capacity. 


\section{TREATMENT OF BISMUTH FRACTION}

Removal of Residual Polonium

Economic considerations require that, in any large scale application of the $\mathrm{DBC}$ solvent extraction process, the aqueous bismuth fraction (IAW stream) be processed to prepare metallic bismuth for further irradiation. For maximum polonium recovery, the processing of irradiated bismuth fuel elements is anticipated within 5 to 10 days after reactor discharge. Under these conditions the lAW stream will contain an appreciable quantity of $210 \mathrm{Bi}$. This isotope has a half 1 ife of about 5 days and decays to 210 Po. Removal of this polonium is necessary to permit contact maintenance techniques in refabricating metallic bismuth fuel elements. Accordingly, it is proposed (26) to store the aqueous $\mathrm{Bi}\left(\mathrm{NO}_{3}\right)_{3}$ solution for about 60 days and then reprocess it again through the $D B C$ extraction process to reduce the polonium concentration to a value considered satisfactory for further processing.

Conceptual Scheme for Preparation of Metallic Bismuth

One conceptual scheme (27) for preparation of metal1ic bismuth from 1 AW solutions, after removal of residual ${ }^{210}$ Po, involves concentration of the bismuth and boiloff of part of the $\mathrm{HNO}_{3}$. Formaldehyde is then added to the resulting solution at 80 to $90{ }^{\circ} \mathrm{C}$ to destroy residual $\mathrm{HNO}_{3}$ and precipitate over $97 \%$ of the bismuth as $\mathrm{BiONO}_{3} \cdot \mathrm{H}_{2} \mathrm{O}$. After centrifugation and washing, the $\mathrm{BiONO}_{3} \cdot \mathrm{H}_{2} \mathrm{O}$ is calcined at about $400{ }^{\circ} \mathrm{C}$ to yield $\mathrm{Bi}_{2} \mathrm{O}_{3}$. Finally, metallic bismuth is obtained by reduction of the $\mathrm{Bi}_{2} \mathrm{O}_{3}$ at about $800^{\circ} \mathrm{C}$ with $\mathrm{CO}$.

Laboratory studies of the concentration and boiloff step, and of the formaldehyde treatment step, were performed as part of this investigation. Results of these studies are discussed in the two succeeding sections. 
Concentration and Acid Boiloff Studies

Qualitative studies showed that $\mathrm{HNO}_{3}$ could readily be removed from dissolver product and extraction column aqueous raffinate solutions by solution boildown. Typical results of these studies are presented in Figure 13. In the experiment illustrated, the $\mathrm{HNO}_{3} / \mathrm{Bi}$ mole ratio was reduced from 1.6 to 0.87 by concentration to the point where bismuth crystals began to form in the boiling solution [about $4 \mathrm{M} \mathrm{Bi}\left(\mathrm{NO}_{3}\right)_{3}$ ]. Approximate relationships between bismuth concentration and the boiling and freezing (or crystallization) points of the resulting solution are shown in Figure 14.

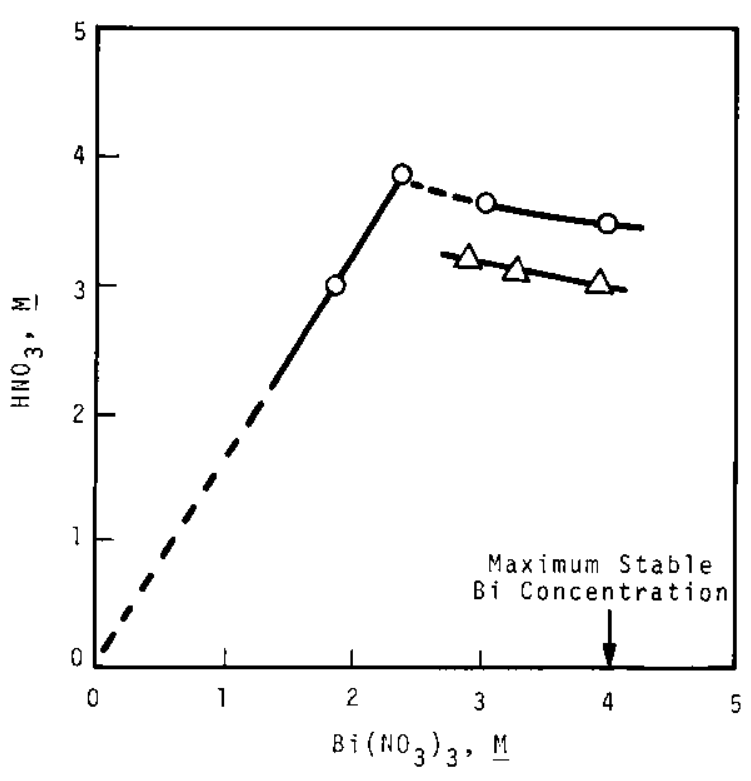

FIGURE 13. HNO 3 Concentrations Resulting from Boizdown of Bi(NO $\left.{ }_{3}\right)^{-}$
$\mathrm{HNO}_{3}$ Solutions

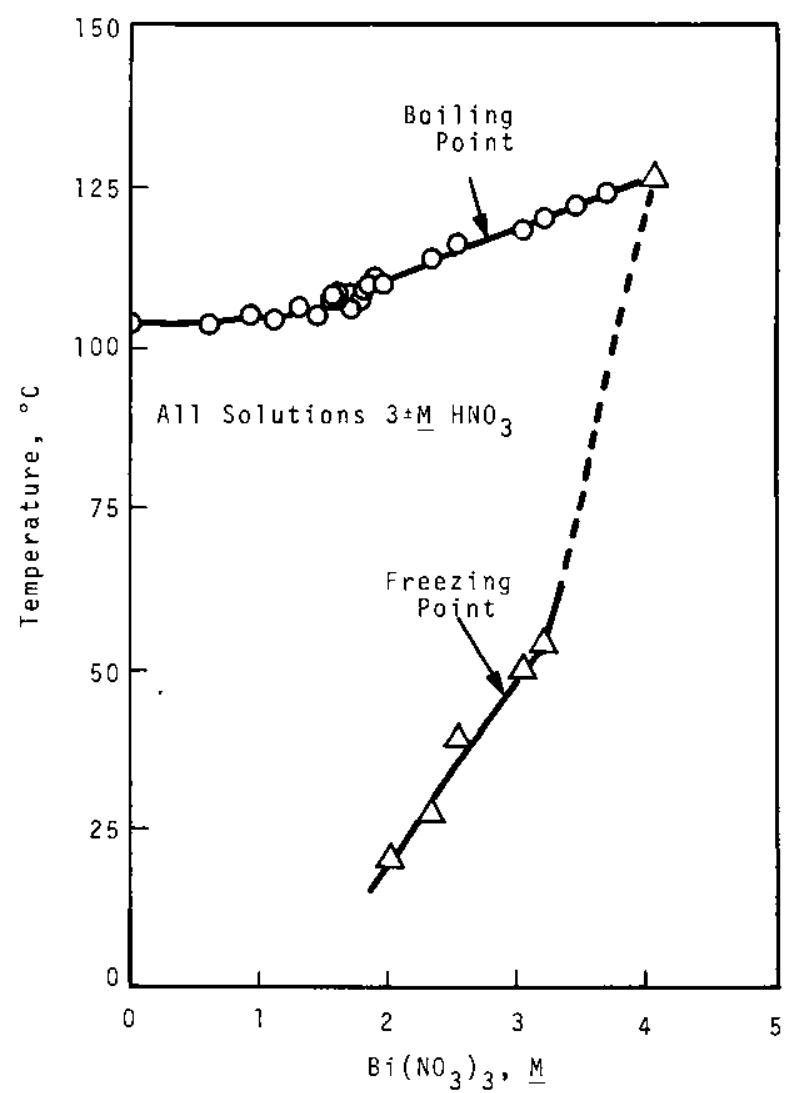

FIGURE 14. Approximate Boiling and Freezing Points of $\mathrm{Bi}\left(\mathrm{NO}_{3}\right)_{3}$ $\mathrm{HNO}_{3}$ Solutions 
An unexpectedly vigorous denitration reaction occurred during the first attempt to concentrate aqueous raffinate produced in cold pilot plant extraction column runs. The reaction, which resulted in pressurization and foam-over of the concentrator, was caused by dissolved and entrained DBC in the aqueous raffinate. Subsequent laboratory measurements indicated the solubility of $\mathrm{DBC}$ in the aqueous raffinate to be $0.5 \pm 0.05$ vol\% independent of $\mathrm{Bi}\left(\mathrm{NO}_{3}\right)_{3}$ and $\mathrm{HNO}_{3}$ concentrations. Evolution of $\mathrm{NO}_{2}$ from boiling raffinates occurred over the temperature range 110 to $114^{\circ} \mathrm{C}$, corresponding to $\mathrm{HNO}_{3}$ concentrations of 3.5 to $4 \mathrm{M}$.

In further tests, the reaction was readily controlled by carefully regulating the boilup rate, and was eliminated completely by steam-stripping the raffinate before it entered the concentrator.

In steam stripping studies, raffinate from solvent extraction runs was fed at 0.8 to $11 / \mathrm{min}$ to the top of an 8 -in. diameter steam stripping tower packed with 4.5 ft of 1 -in. stainless steel Raschig rings. The solution passed countercurrent to steam derived from the concentrator while the boilup rate was set to keep the concentrator volume constant. Essentially complete $D B C$ removal was indicated by the lack of a denitration reaction in the concentrator and by the absence of the typical rancid odor of $D B C$ degradation products in the concentrator.

Precipitation of Bismuth

The aqueous $\mathrm{Bi}\left(\mathrm{NO}_{3}\right)_{3}$ raffinate produced in plant scale operations will contain various metal impurities. These impurities will be introduced as corrosion products and/or as contaminants in process chemical reagents. Certain isotopes of the 1ikely impurities (e.g. ${ }^{50} \mathrm{Cr},{ }^{58} \mathrm{Fe},{ }^{59} \mathrm{Co}$ ) are critical in the sense that they would undergo neutron activation during 
irradiation of the bismuth and become troublesome gamma and beta emitters in the bismuth during refabrication and reactor charging operations in the following cycle.

Precipitation of the bismuth from the raffinate as $\mathrm{BiONO}_{3} \cdot \mathrm{H}_{2} \mathrm{O}$ not only provides a convenient starting material for preparation of $\mathrm{Bi}_{2} \mathrm{O}_{3}$, but also provides a process step to achieve partial decontamination of the bismuth from metaliic impurities. Determination of the extent of such decontamination was the primary purpose of the precipitation studies discussed in this section.

The exact type and concentration of impurities present in the aqueous bismuth raffinate produced in plant scale application of the DBC has not been established. The composition of the synthetic lAW solution used in these studies (Table XIII) was selected to provide what is believed to be a representative spectrum of impurities and concentrations. For convenience only, molybdenum was added as $\left(\mathrm{NH}_{4}\right)_{6} \mathrm{Mo}_{7} \mathrm{O}_{24}$; antimony and tantalum were added only as radioisotopes. After addition of radioisotopes, $1 \mathrm{AW}$ solutions were allowed to stand 5 to 7 days before precipitation of bismuth.

The results in Table XIII were obtained, in each case, by adding, at about $70{ }^{\circ} \mathrm{C}, 4.0 \mathrm{~m} 1$ of $13.3 \mathrm{M}$ formaldehyde to $10 \mathrm{~m} 1$ of synthetic $1 \mathrm{AW}$ solution containing the appropriate radioisotope. The resulting mixture of 1 iquid and $\mathrm{BiONO}_{3} \cdot \mathrm{H}_{2} \mathrm{O}$ precipitate was digested one hour at boiling temperature, cooled to $25^{\circ} \mathrm{C}$, and centrifuged. After removal of the liquid, the precipitate was washed once at $25^{\circ} \mathrm{C}$ with a volume of water equal to the volume of centrifuged precipitate (about $2 \mathrm{ml}$ ). The wash liquid was removed, and the precipitate was dissolved in about $10 \mathrm{ml}$ of $10 \mathrm{M} \mathrm{HNO}_{3}$.

The washed bismuth precipitate contained only traces of iron, chromium, manganese, cobalt, and sodium. However, decontamination from silver was slight, and essentially all the tantalum and antimony followed the bismuth. 


\section{TABLEXIII. Precipitation of $\mathrm{BiONO}_{3} \cdot \mathrm{H}_{2} \mathrm{O}-$}

Conditions: $\quad \mathrm{BiONO}_{3} \cdot \mathrm{H}_{2} \mathrm{O}$ precipitated from synthetic $1 \mathrm{AW}(\mathrm{a})$ containing Indicated radioisotopes and washed with water as described in text.

Radioisotopes Decontamination Factor ${ }^{(b)}$

$\begin{array}{lc}{ }^{59} \mathrm{Fe} & 16 \\ { }^{51} \mathrm{Cr} & 26 \\ { }^{54} \mathrm{Mn} & 18 \\ { }^{22} \mathrm{Na} & 27 \\ { }^{60} \mathrm{Co} & 30 \\ 110 \mathrm{Ag} & 5 \\ 182 \mathrm{Ta} & 1.3 \\ 125 \mathrm{Sb} & 1.3\end{array}$

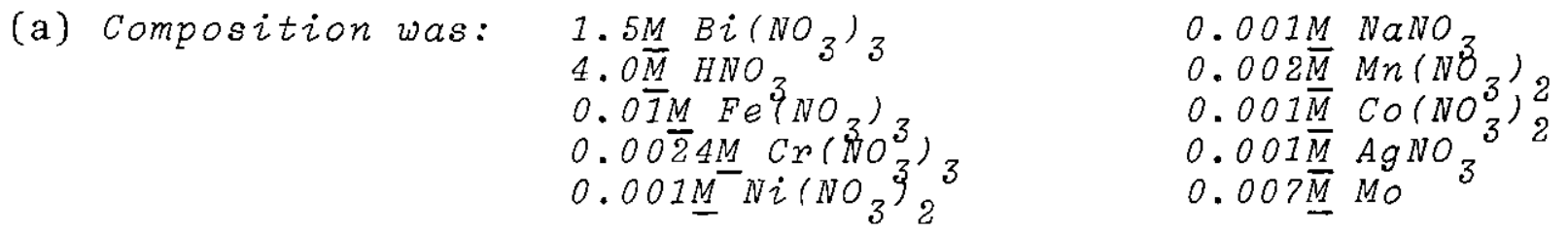

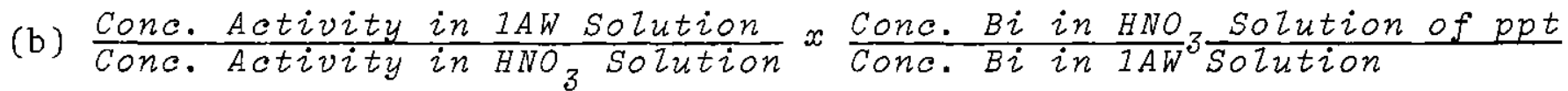

The precipitation - denitration procedure outlined above yielded a dense, easily centrifugable cake. About $99 \%$ of the bismuth precipitated when $4 \mathrm{ml}$ of $13.3 \mathrm{M}$ formaldehyde was added to $10 \mathrm{ml}$ of the 1AW; the terminal acidity was about $0.8 \mathrm{M}$. Bismuth recoveries were smaller (54 to $93 \%$ ) when smaller amounts ( 2.5 to $3.5 \mathrm{~m} 1$ ) of the formaldehyde reagent were added.

The bismuth precipitate obtained by the formaldehyde treatment contained $66.2 \mathrm{wt} \%$ bismuth; $\mathrm{BiONO}_{3} \cdot \mathrm{H}_{2} \mathrm{O}$ contains $68.5 \mathrm{wt} \%$ bismuth. The differential analysis thermogram of the bismuth precipitate was identical to that of Fisher Scientific Co. reagent grade bismuth subnitrate. However, the $x$-ray powder diffraction pattern (Table B-1) of the precipitated solid did not correspond to that given in the ASTM file for $\mathrm{BiONO}_{3} \cdot \mathrm{H}_{2} \mathrm{O}$. 


\section{TREATMENT OF POLONIUM FRACTION}

The DBC solvent extraction process described in this paper is just one part of the overall polonium production scheme. Its function is to recover the ${ }^{210}$ Po and to free it from the bulk of the associated bismuth. Further purification and treatment of the separated ${ }^{210}$ Po is necessary to obtain material suitable for preparation of power sources. Technology for these latter process steps has been proposed and/or developed by various other investigators $(26,28)$ and is reviewed only briefly here.

One process proposed for final purification of the polonium fraction utilizes technology developed at the Mound Laboratory. (1) In this scheme, the dilute $\mathrm{HNO}_{3}$ product stream from the solvent extraction process is treated with HCl and formic acid to destroy nitrate ion and convert to a chloride system. Subsequently, polonium is reduced to the metal by addition of $\mathrm{SnCl}_{2}$, while the bulk of the bismuth remains in the aqueous phase. If further purification is required before encapsulation, the polonium metal can be dissolved in a $\mathrm{HCl}-\mathrm{H}_{2} \mathrm{O}_{2}$ solution and again precipitated by reduction with $\mathrm{SnCl}_{2}$. Alternative processes suggested for purification of the polonium product include a second cycle of solvent extraction and electrolytic deposition of polonium metal directly from the dilute $\mathrm{HNO}_{3}$ product solution.

\section{ACKNOWLEDGEMENT}

The assistance and cooperation of L. C. Nei1, D. G. Bouse, G. C. LaBorde, and R. C. Niemuth in performing the many experimental studies is gratefully acknowledged. Special thanks are due also to D. S. Skeie for obtaining all the $x$-ray powder diffraction data reported herein. 


\section{REFERENCES}

1. H. V. Moyer, editor. Polonium, TID-5221. Mound Laboratory, Miamisburg, Ohio, 1956 .

2. R. E. Blanco and C. D. Watson. "Headend Process for Solid Fuels," Reactor Handbook, edited by S. M. Stoller and R. B. Richards. Interscience Publishers, New York, 1961. vol. II, p. 48 .

3. G. M. Rutten and J. M. Van Bemmelen. "Das System Wismutoxgd, Salpetersaure und Wasser," 2. Anorg. Chem., vol. 30, pp. 342-405. 1902 .

4. K. Bagnalz. The Chemistry of Selenium, Tellurium, and Polonium. Elsevier Publishers, New York, 1966.

5. A. E. Cairo. "Separation of Polonium with Diisopropylketone," Paper No. 1028, First International Conference on the Peaceful Uses of Atomic Energy, Geneva, Aug. 8-20, 1955. vol. 7, pp. 331-335. United Nations, Geneva, 1956.

6. N. Matsuura and M. Haissinsky. "The Six-Valent State of Polonium," J. Chim. Phys., vol. 55, pp.475-482. 1958.

7. N. Matsuura, A. Ouchi, and M. Kojima. "Studies on Extraction of Polonium by Hexone from Acid Solutions," Bulz. Chim. Soc. Japan, vol. 34, pp. 411-416. 1961.

8. J. Donnan and A. A. L. Zamith. "Solvent Extraction of Polonium from Nitric Acid Solutions," Nature, vol. 177, pp. 746-747. 1956 .

9. J. C. Sheppard. The Extraction of Polonium(IV) and Bismuth (III) from Nitric Acid by Several Organic Solvents, HW-83226. General Electric Co., Richland, Washington, July, 1964 .

10. J. C. Sheppard. The Distribution of Polonium-210 and Bismuth-210 Between Linear Aliphatic Ethers and Nitric Acid Solutions, BNWL-735, Pacific Northwest Laboratory, Richiand, Washington, September, 1966.

11. G. R. Howezls, T. G. Hughes, D. R. Mackey, and K. Saddington. "The Chemical Processing of Irradiated Fuels from Thermal Reactors," Paper No. 307, Second International Conference on the Peaceful Uses of Atomic Energy, Geneva, September 1-13, 1958, vol. 17, pp. 3-24. United Nations, Geneva, 1958. 
12. C. M. Nichols. "The Development of the Butex Process for the Industrial Separation of Plutonium from Nuclear Reactor Euels," J. British Nucl. Energy Conf., vol. 3, pp. $279-289$. 1958 .

13. R. F. Hibbs and A. E. Sands. "Highly Enriched or Fully Enriched Uranium Recovery," Reactor Handbook, edited by $S$. M. Stolzer and $R$. B. Richards. Interscience Publishers, New York, 1961. vol. II, p. 413.

14. C. D. Susano. Reactivity of Dibutyl Carbitol, H-1.740.8. PA II. CZinton Engineer Works, Tennessee Eastman Corp., oak Ridge, Tennessee, April, 1947.

15. A. F. Ferris, K. W. MacLean, I. G. Marks, and W. D. Emmons. "Metathetical Reactions of Silver Salts in Solution-III. The Synthesis of Nitrate Esters," J.Am. Chem. Soc., vol. $75, p .4078 .1953$.

16. N. Kornblum, B. Taub, and H. E. Ungnade. "The Reaction of Silver Nitrite with Primary Alkyl Halides," J.Am. Chem. Soc., vol. 76, pp. 3209-3211. 1954.

17. T. F. Evans. Pizot Plant Dissolution of Unjacketed Fuel Elements, HW-46093. General Electric Co., Richland, Washington, October, 1956.

18. H. A. C. MCKay and R. J.W. Streeton. "Extraction of Uranium(IV) Nitrate by Tri-n-Butyl Phosphate and by Dibutyl Carbitol," J. Inorg. Nucl. Chem., vol. 27, pp. 879-884. 1965 .

19. G. Chariot. Colorimetric Determination of Elements, Elsevier Publishers, New York, 1964. p. 199.

20. J. G. Michaelson. Unpublished Data. Pacific Northwest Laboratory, Richland, Washington, 1965. (Personal Communication)

21. D. G. Tuck. "Solvent Extraction Studies. Part I. Nitric Acid Species in Dibutyl Carbitol (Diethylene Glycol Dibutyl Ether)," Chem. Soc.J.Pt. 3, pp. 32023206. 1957 .

22. B. V. Copzan, J.K. Davidson, and E. L. Zebroski. "The 'Pump-Mix' Mixer-Settier - A New Liquid-Liquid Extractor," Chem. Eng. Prog., vol. 50, pp. 403-408. 1954. 
23. R. E. Emmert and R. L. Pigford. "Gas Absorption and Solvent Extraction," Perry's Chemical Engineer's Handbook, edited by R. H. Perry, C. H. Chilton, S. O. Kirkpatrick, McGraw-Hill Book Co., New York, 1963. Fourth edition. Chapter 14.

24. C.N.R. Rao. Ultra-Violet and Visible Spectroscopy. Butterworths Publishers, London, 1961. p. 21.

25. K. W. Bagnall, D. S. Robertson, and M. A. A. Stewart. "The Polonium Nitrates," Chem. Soc.J. Pt. 3, vol. 3, pp. 3633-3636. 1958 .

26. T. R. McKenzie. Isochem, Inc., Richland, Washington, 1965. (Personal Communication)

27. W. J. Guay. Unpublished Data. Pacific Northwest Laboratory, Richland, Washington, 1965. (Personal Communication)

28. L. E. Bruns. Isochem, Inc., Richland, Washington, 1965. (Personal Communication) 
BNWL - 584

APPENDIX A

PILOT PLANT RUN DATA 

TABLEA-1. Feed Stream Compositions for Pilot Plant Runs

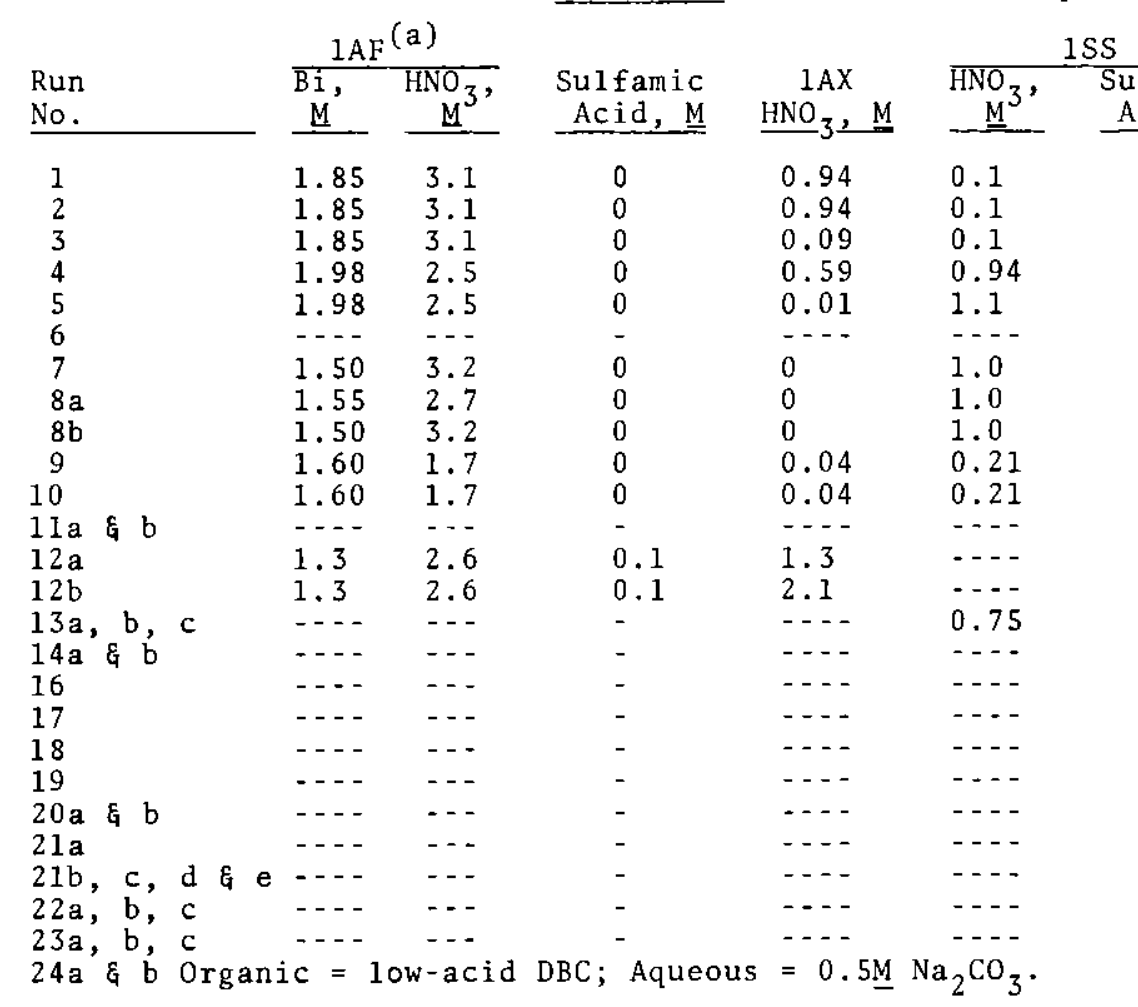

\begin{tabular}{|c|c|c|c|}
\hline \multirow[b]{2}{*}{$\begin{array}{c}1 S F \\
\mathrm{HNO}_{3}, \underline{\mathrm{M}} \\
\end{array}$} & \multicolumn{2}{|c|}{$1 C X$} & \multirow[b]{2}{*}{$\begin{array}{r}1 \mathrm{CF} \\
\underline{\mathrm{HNO}}_{3}, \underline{\mathrm{M}}\end{array}$} \\
\hline & $\stackrel{\mathrm{HNO}}{3}_{3} 2 \mathrm{M}$ & $\begin{array}{l}\text { Oxalic } \\
\text { Acid, } \mathrm{M}\end{array}$ & \\
\hline 1.6 & 0.1 & 0 & 0.01 \\
\hline$\ldots$ & 0.1 & 0 & $\ldots$ \\
\hline 2.6 & 0.1 & 0 & 0.36 \\
\hline 2.1 & 0.1 & 0 & 0.25 \\
\hline 2.2 & 0.1 & 0 & 0.32 \\
\hline-- & 0 & 0 & 2.5 \\
\hline - - - & 0 & 0 & 1.7 \\
\hline - - - & 0 & 0 & 1.9 \\
\hline - - - & 0 & 0 & 1.6 \\
\hline 1.1 & - & - & $\ldots$ \\
\hline 1.4 & - & - & $\ldots$ \\
\hline$-\ldots$ & 0 & 0 & 0.07 \\
\hline$\cdots$ & - & - & $-\cdots$ \\
\hline - - - & - & - & $\cdots$ \\
\hline 1.9 & - & - & --- \\
\hline$-\cdots$ & 0 & 0 & 0.74 \\
\hline - - - & 0 & 0 & 2.1 \\
\hline - - & 0 & 0 & 2.1 \\
\hline- & 0 & 0 & 2.1 \\
\hline - - - & 0 & 0 & 2.1 \\
\hline - - - & 0 & 0 & 1.7 \\
\hline - - - & 0 & 0 & 0.16 \\
\hline$\ldots$ & 0 & 0 & 2.2 \\
\hline - - - & 0.52 & 0.2 & 1.4 \\
\hline & 0.2 & 0.2 & 1.4 \\
\hline
\end{tabular}

(a) Freshly dissolved bismuth feed was used in Runs 1, 2, 3, 8a, 9, and 10 . Alt other runs used recycled
bismuth (concentrated $1 \mathrm{AW}$ ) 
TABLE A-2. Pilot Plant Pulse Column Run Summaries

Cartridge: $1 \mathrm{~A}=19.4 \mathrm{ft}$ of 4 -in.-spaced, $23 \%$ free area nozzle plates with $3 / 16$-in. holes

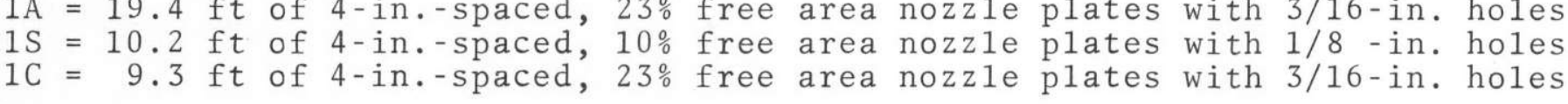

Ambient. Pulse amplitude: 1 -in. except where noted. See Table $A-1$ for feed
stream compositions. Columns operated in cascade $1 \mathrm{~A} \rightarrow 1 \mathrm{~S} \rightarrow 1 \mathrm{C}$ or $1 \mathrm{~A} \rightarrow 1 \mathrm{C}$.

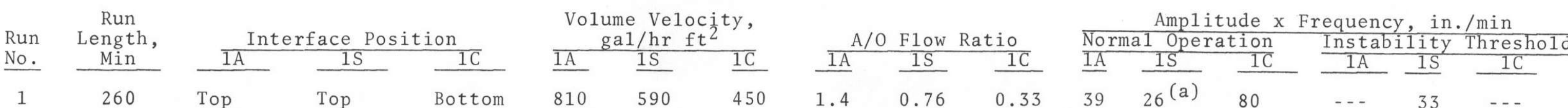

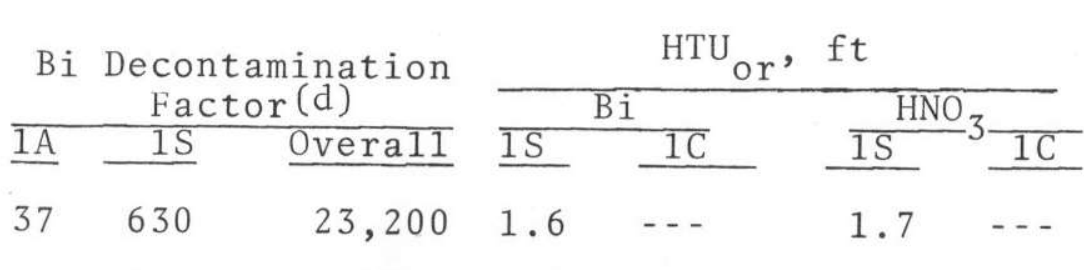

Remarks

Top Top Bottom

$\begin{array}{llllll}1.4 & 0.76 & 0.33 & 39 & 26^{(a)} & 80\end{array}$

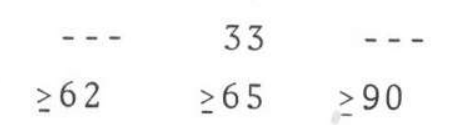

$37 \quad 630$

Flooding test

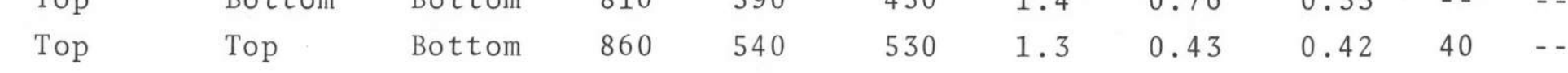

$\begin{array}{lllllllll}\text { Bot tom } & 810 & 570 & 550 & 1.3 & 0.65 & 0.58 & 40 & 32\end{array}$

80

440 (c) $-\cdots$

$51 \quad 920$

$47,200 \quad 1.5$

$\cdots$

freq. not recorded.

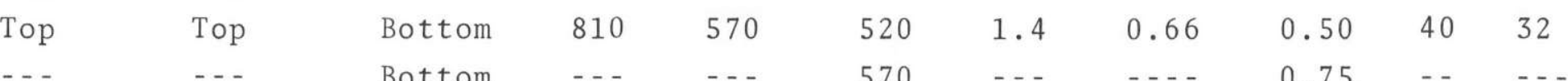

Bottom - - - Bottom

$\geq 40^{\text {(c) }}$

$44 \quad 3300$

$44,000 \quad 1.3$

-.. (2.3)

$\begin{array}{lll}0.75 & -- & - \\ 0.74 & 96 & -\end{array}$

Bottom

$0.76 \quad 54 \quad-10$ 
PABLEA-3. Pilot Plant Packed Column Run Summaries

Packing $=3 / 4-i n$. stainless stee 1 Raschig ring

Packing $=3 / 4-$ in. stainless steel Raschig rings
Interface $=$ Top Pulse Amplitude (when used) $=1.0$ in
See Table A-1 for feed stream composition.

\begin{tabular}{|c|c|c|c|c|c|}
\hline $\begin{array}{l}\text { Run } \\
\text { No. }\end{array}$ & $\begin{array}{l}\text { Type of } \\
\text { Column }\end{array}$ & $\begin{array}{c}\text { Run } \\
\text { Length, } \\
\text { Min } \\
\end{array}$ & $\underset{\mathrm{Temp}}{\mathrm{C}}$, & $\begin{array}{l}\text { Packed } \\
\text { Ht... ft }\end{array}$ & $\begin{array}{l}\text { Volume Velocity } \\
\text { gal/hr-ft }\end{array}$ \\
\hline $12 \mathrm{a}$ & $1 \mathrm{~A}$ & 160 & 23 & 19 & 1730 \\
\hline $12 \mathrm{~b}$ & $1 \mathrm{~A}$ & 150 & 50 & 19 & 2010 \\
\hline $13 a$ & is & 60 & 20 & 19 & $1260 \pm 100$ \\
\hline $13 \mathrm{~b}$ & $1 \mathrm{~s}$ & 30 & 46 & 19 & 1360 \\
\hline $13 \mathrm{c}$ & is & 120 & 50 & 19 & 1130 \\
\hline $11 a$ & $1 \mathrm{C}$ & 120 & 22 & 19 & $1460 \pm 100$ \\
\hline $11 \mathrm{~b}$ & IC & 60 & 22 & 19 & 1210 \\
\hline $14 a$ & $1 \mathrm{C}$ & 60 & 54 & 19 & 1610 \\
\hline $14 \mathrm{~b}$ & $1 \mathrm{C}$ & 30 & 54 & 19 & $1760 \pm 150$ \\
\hline 16 & $1 \mathrm{C}$ & 60 & 25 & 10 & 810 \\
\hline 17 & $1 \mathrm{C}$ & 40 & 25 & 10 & 1070 \\
\hline 18 & $1 \mathrm{C}$ & 30 & 25 & 10 & 1490 \\
\hline 19 & $1 \mathrm{C}$ & 50 & 50 & 10 & 1490 \\
\hline $20 a$ & $1 \mathrm{C}$ & 35 & 25 & 19 & 1300 \\
\hline $20 \mathrm{~b}$ & IC & 60 & 25 & 19 & 1300 \\
\hline $23 \mathbf{a}$ & 1C & 55 & 53 & 19 & 1560 \\
\hline $23 b$ & IC & 60 & 50 & 19 & 1560 \\
\hline $23 c$ & IC & 40 & 50 & 19 & 1560 \\
\hline $24 a$ & 10 & - & 27 & 19 & $810 \pm 110$ \\
\hline & 10 & -- & 48 & 19 & $980 \pm 80$ \\
\hline
\end{tabular}

\begin{tabular}{|c|c|c|c|c|c|c|}
\hline $\begin{array}{l}\text { A/O } \\
\text { Flow } \\
\text { Ratio } \\
\end{array}$ & $\begin{array}{c}\text { Ampl } x \\
\text { in. } / m \\
\text { Operating }\end{array}$ & $\begin{array}{l}\text { q, } \\
\text { Flood }\end{array}$ & $\begin{array}{l}\mathrm{Bi} \\
\mathrm{DF}\end{array}$ & $\begin{array}{l}\mathrm{HTU}_{0} \\
\mathrm{Bi}\end{array}$ & $\begin{array}{l}., \mathrm{ft} \\
\underline{\mathrm{HNO}}_{3}\end{array}$ & Remarks \\
\hline $\begin{array}{l}0.46 \\
0.41 \\
0.20 \\
0.20 \\
0.17\end{array}$ & $\begin{array}{l}0 \\
0 \\
0 \\
0 \\
0\end{array}$ & $\begin{array}{l}\cdots \\
\cdots \\
\cdots- \\
\cdots- \\
\cdots-\end{array}$ & $\begin{array}{c}8.1 \\
16 . \\
\cdots- \\
>570\end{array}$ & $\begin{array}{c}\cdots \\
\cdots \\
\cdots \\
\leq 2 \\
\leq 2.9\end{array}$ & $\begin{array}{l}-- \\
\cdots \\
\cdots \\
\cdots \\
-\cdots\end{array}$ & $\begin{array}{l}\text { Near flood } \\
\text { Stable(a) } \\
\text { Flooding test } \\
\text { Stable }\end{array}$ \\
\hline $\begin{array}{l}0.67 \\
1.0 \\
1.0 \\
1.0 \\
1.6 \\
1.4 \\
1.2 \\
1.2 \\
1.2 \\
1.2 \\
1.1 \\
1.1 \\
1.1\end{array}$ & $\begin{array}{r}0 \\
0 \\
0 \\
0 \\
0 \\
0 \\
0 \\
0 \\
- \\
40 \\
0 \\
47 \\
-\end{array}$ & 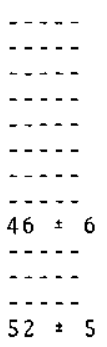 & 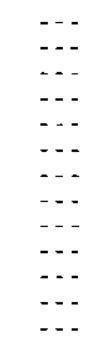 & 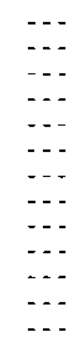 & $\begin{array}{r}-. . \\
5.3 \\
\leq 3.8 \\
3 . . \\
3.0 \\
3.1 \\
3.0 \\
2.8 \\
-.- \\
3.4 \\
5.5 \\
4.7 \\
\ldots-.\end{array}$ & $\begin{array}{l}\text { Flooding test } \\
\text { Flooding test }\end{array}$ \\
\hline $\begin{array}{l}0.58 \\
0.53\end{array}$ & $\begin{array}{l}0 \\
0\end{array}$ & 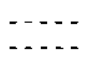 & $\cdots$ & $\cdots$ & $\cdots$ & $\begin{array}{l}\text { Flooding test } \\
\text { Flooding test }\end{array}$ \\
\hline
\end{tabular}

(a) Good dispersion over operating range of 500 to $2010 \mathrm{gal} / \mathrm{hr} \mathrm{ft}^{2}$ 

BNWL - 584

APPENDIX B

X-RAY POWDER DIFFRACTION DATA 

$\underline{T A B L E ~ B-1} \cdot \quad X$-Ray Powder Diffraction Data (Cu $K_{\alpha}$ Radiation)

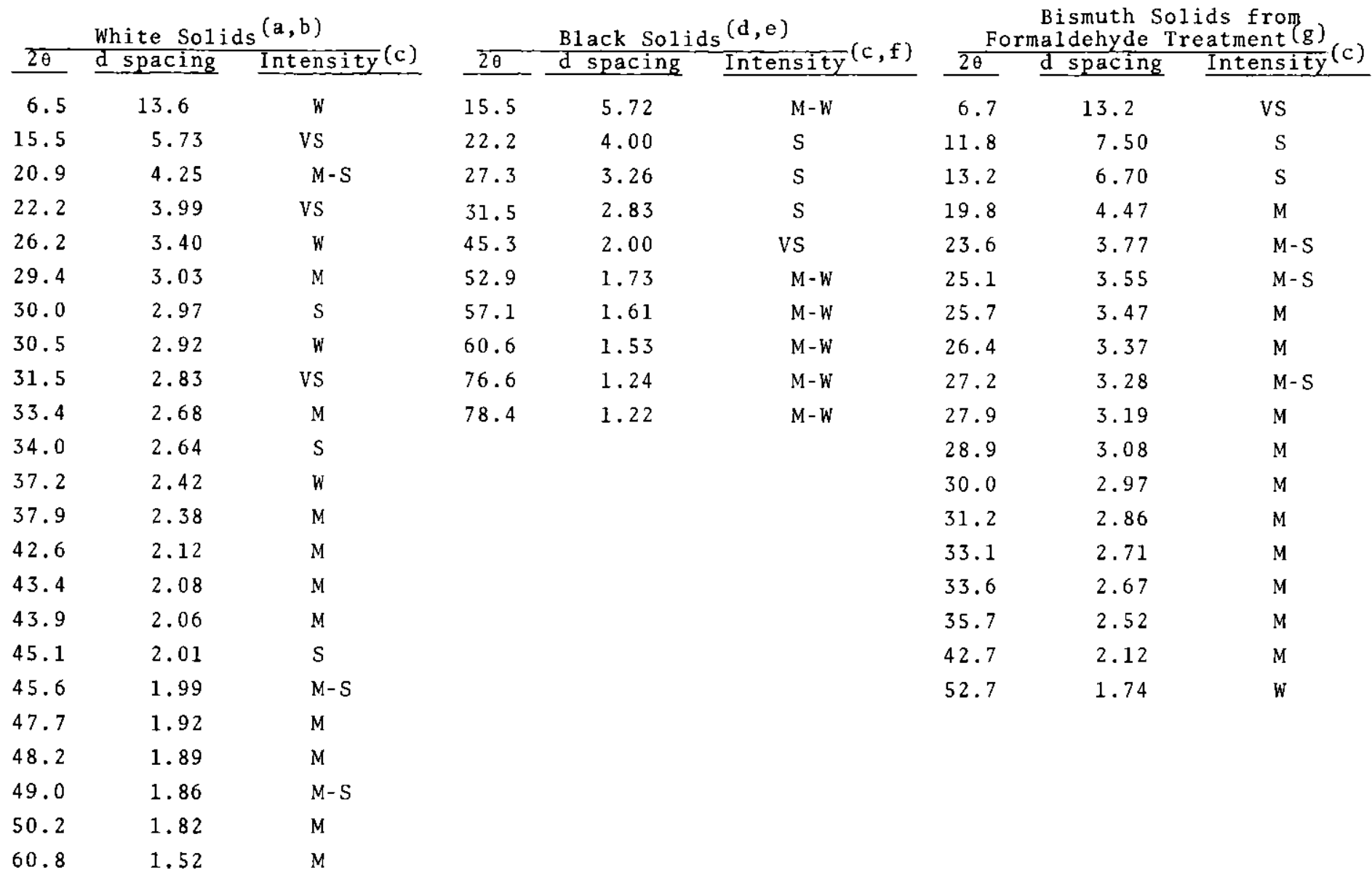

(a) White solids obtained from synthetic lAP (see p.41)

(b) Powder pattern obtained with General Electric Co., XRD-5 diffractometer

(c) Intensity Key: VS - Very strong $M$ - Moderate

(d) Black solids obtained frong W- Weak

(d) Black solids obtained from mixer-settler $1 A P$ (see p.41)

(f) Sample exhibited severe line broadening and only the stronger lines could be measured.

(g) See p. 48 for preparation of compound. 



\section{DISTRIBUTION}

Number

of Copies

2

AEC, Chicago Patent Group

G. H. Lee

R. K. Sharp, Richland

AEC Division of Technica1 Information Extension

AEC, Richland Operations Office

C. L. Robinson

Technical Information Library

Atlantic Richfield Hanford Co.

S. J. Beard

L. E. Bruns

H. H. Hopkins

H. C. Rathvon

A. E. Smith

P. W. Smith

R. E. Tom 1 inson

Technical Information Files

Battelle-Northwest

J. M. Atwood

A. G. Blasewitz

L. L. Burger

R. E. Burns

C. R. Cooley

G. M. Dalen

D. R. de Halas

K. M. Harmon

G. Jansen

R. L. Moore

G. L. Richardson

C. A. Rohrmann

W. W. Schulz (9)

J. C. Sheppard

E. E. Voiland

Technica1 Information Files

Technical Publications 


